\title{
Index for Volume 88
}

AUTHOR AND SUBJECT INDEX. Pages indicating errata are in italic. "S" indicates September abstract supplement. Publication number P-1998-1026-01O.

Abawi, G. S., S97

Abbas, H. K., S1

Abbasi, P. A., S63

Abdul-Kader, A. M., S134

Abdullah, M. T., S1

Abelmoschus spp., Verticillium wilt, resistance inheritance, S72

Abies religiosa, decline, in Mexico City, S3

Abney, T. S., S113, S115

Aboshosha, S. S., S1

Abou-Zaid, M., 396

Abouzid, A., S1, S82, S122

Abstracts, author index of APS annual and division meeting presentations, $\mathrm{S} 138$

Acetobacter diazotrophicus, on sugarcane, strains in Louisiana, S53

Acidovorax avenae, on watermelon, seed detection, $\mathrm{S} 92$

Acosta, J., 292

Acosta-Leal, R., S1

Acremonium spp., growth in spaceflight conditions, pathogenicity, $\mathrm{S} 42$

-A. cucurbitacearum, virulence assessment, colony forming units and plant response, S72

Acuna, I. A., S2

Adams, G. C., 376, S110

Adams, P. D., S2

Adaskaveg, J. E., S29, S62, S84, S107

Adee, E. A., S2

Adrian, M., 472, 740

Aegerter, B. J., S2

African cassava mosaic virus, detection and identification, immunoassay, 1302

Agama, K., S2

Agaricus sp., green mold, fungus associations, S50

-A. bisporus: Trichoderma green mold, aerobiology, S134; Trichoderma green mold, epidemics, S4; Trichoderma harzianum association, electron microscopy, S134

Agnew, M., S2

Agrobacterium tumefaciens

- cell morphology in tumors, S53

-oncogenic suppressant, Osa analysis, S16

-T-pilus, genetic and biochemical characterization, S51

Agrostis stolonifera (see also Bentgrass and Turfgrass)

- Rhizoctonia blight, assessment by radiometry, 446

Aigbokhan, E. I., 563

Aist, J. R., S21

Alabouvette, C., 30

Alameda, M., S121

Alarcón, C., 306

Albibi, R., S5

Albugo candida, controlled by bacterium, $\mathrm{S} 89$

Alcantara, T., S2

Al-Dahmani, J., S3, S63

Aldwinckle, H. S., S8, S134, S136

Alexander, S. A., S3, S128

Alfalfa

— foliar diseases, sunlight and canopy effect, S115

- Nectria haematococca MAK1 gene, S65

—root rot, new in Wyoming, S39

-yield response model, comparison, S111

Alfalfa mosaic virus, Verticillium wilt and cold stress interaction, S64

Ali, S., S114

Alioto, D., 1200

Allan, M. A., S3, S79, S136

Allen, C., S41, S51

Allen, E., S63

Allen, R. I., S22
Allen, T. W., Jr., S3

Alleyne, A. T., S120

Allium porrum (see also Onion)

—bacterial blight, new pathovar, 844

Al-Menoufi, O. A., S25

Almond

- anthracnose, epidemiology in California, S107

- lethal canker, Phytophthora spp. implicated, S12

Alonso-Prados, J. L., 520

Al-Rehiayani, S., S3

Alternaria spp., phylogenetics, mitochondrial DNA sequences, $\mathrm{S} 73$

-A. alternata, on citrus, environmental factors, 1218

-A. helianthi, mycoherbicide, adhesive vesicles, $\mathrm{S} 1$

-A. solani: on potato, primary inoculum source,

S108; on tomato, leaf assay for resistance evaluation, S33

-A. zinniae, oxygen for control, $\mathrm{S} 102$

Alvardo-Rosales, D., S3

Alvarez, A. M., S30

Amador, J. M., S122

Ambrosiella sp., on spruce, bark beetle association, 39

American Phytopathological Society

—abstracts, author index, S138

—annual report, 15

-excellence in extension award, 24

- excellence in teaching award, 25

-fellows, 20

-Lee M. Hutchins award, 25

- Novartis award, 26

-officers, representatives, and committees, 13

—presidential address, 17

-Ruth Allen award, 27

Ames, K. A., S3

Anagnostakis, S. L., 598

Anandalakshmi, R., S3

Anas, O., S4, S66

Andary, C., 1141

Anders, J. M., S19

Anderson, A. J., S42, S47, S48, S62

Anderson, C. M., 456, S4

Anderson, E., S2

Anderson, J. A., S24, S25

Anderson, J. M., 851

Anderson, L. M., S85

Anderson, M. G., S4, S134

Anderson, N. A., S35

Anderson, T. W., S4, S89

Ando, I., 822

Andrade, G. P., S71

Andrejeva, J., 311

Andrews, J. H., S4, S12, S110

Andrianifahanana, M., S82

Andries, C., S4

Angel, J. C., S122

Angwin, P. A., S4

Anisogramma anomala, ascospore

- discharge pattern, 1165

-release factors, 122, S108

Annis, S., S89

Annis, S. L., S131

Ant, Fusarium oxysporum dispersal by, 185

Anthurium, blight, pesticide effect on biocontrol, S30

Antibiotics, helvolic and fusidic acids, phytotoxicity, S38

Aphanomyces spp.

-A. cochlioides, on sugar beet, population structure, S24

-A. euteiches: on pea, diversity, 915; on pea, oospores and enzymatic activity, 992; strains, variation, 52,272
Aphelenchoides ritzema-bosi, in Colorado, $\mathrm{S} 107$

Apoptosis (see Programmed cell death)

Appel, D. N., S88

Apple

— autumnal shoot blight, in West Virginia, S132

-blue mold: biocontrol and resistance mechanisms, S21; control by Candida sake, 960

-fire blight: antagonists in inoculum preparation, 506; migration in host tissue, 416

-postharvest decay: biocontrol and factors, S18; Pichia anomala for Botrytis cinerea, 335

- promoter gene transfer from potato to apple rootstock, S134

-replant disease, microbial complex in Washington, 930

— scab: ascospore discharge factors, 902; endochitinase transgenic lines, resistance, S136

—soil microarthropod, IPM relation, S4

Apple stem grooving virus, chemotherapy, PCR detection, S43

Apricot latent virus, on stone fruits, S66

Arabidopsis, bacterial speck, systemic acquired resistance, 450

Arabidopsis thaliana

—bacterial wilt, resistance, 330

-cauliflower mosaic virus on, resistance-breakage, S2

Aragaki, M., S45, S90

Aranda, M. A., 520

Arce-Johnson, P., 306

Ardales, E. Y., S4

Arevalo, M., S11

Aris, V. M., S5

Armengol, J., S72

Armillaria spp., nuclear status and genome size of isolates, $\mathrm{S} 47$

-A. cepistipes, mating with North American biological species, S60

Armstrong, S. D., S128

Arumuganathan, K., S47

Asensio, M., 198

Ash

—arbuscular mycorrhizal fungi, Arizona, S86

- phytoplasma, leafhopper carriers in New York, S38

—witches'-broom, yellows relation, S93

-yellows, detection in Great Plains and Rocky Mountains, S93

Aspen (see also Populus tremuloides)

- thinning, insects, and diseases, S95

Aspergillus spp.

-A. flavus: aerial sampling, in Arizona, S8; alpha-amylase deficient mutant, S28; alpha-amylase production, corn trypsin inhibitor and host resistance, S16; antifungal activity against, peptide, S65; on corn, kernel resistance and protein, 276; other Aspergillus spp., distribution in Arizona, S10

-A. parasiticus, averufin-accumulating mutant, complementation, S98

Aspidistra elator, southern blight, new disease, S61 Astua-Monge, G., S5, S20

Avena fatua, in wheat, wheat leaf rust severity affected by, 708

Avila, F. J., 428

Aycock, R., 29

Ayllón, M. A., 685

Azospirillum, arbuscular mycorrhizal fungi synergistic to, in tissue culture, $\mathrm{S} 82$

Baayen, R. P., 30

Bachman, M. S., S3

Bacillus subtilis, foliar fungal pathogens controlled by, S60 
Backman, P. A., S27

Bacon, C. W., S32

Bai, J. F., S91, S114

Bailey, B. A., 185

Bailey, J. E., S5, S53

Baizhanov, M. K., S89

Baker, B. J., S39

Baker, F. A., S5

Balbalian, C. J., S128

Balesdent, M. H., 1210

Ball, J. J., S93

Banana

—burrowing nematode, phenol effect in roots, 1141

-Fusarium wilt: genetic variation in vegetative compatibility groups, 1283; resistance in Florida, S72

- Sigatoka and Cordana leaf spot, keyplex effect, S122

Banana streak badnavirus, detection with PCR assay, S20

Bandla, M. D., 98

Banks, D., S5

Bannwart, D. L., S5

Bao, Y., S5, S52

Barak, J. D., S6

Barash, I., S6

Barbercheck, M. E., S66

Barczynska, H., S28

Barley

- covered smut, mating inhibitor, pheromone, 456

-Drechslera teres, induced resistance, 698

-Fusarium head blight, genotype evaluation, S27

-leaf rust, resistance genes $R p h 9$ and $R p h 12,76$

- mildew resistance genes, chitinase genes affected by, S50

—net and spot blotch, resistance sources, S85

-phylloplane, Rhodosporidium toruloides, adhesion, $\mathrm{S} 110$

- powdery mildew, resistance genes, cell death pathways, S103

-rust, prehaustorial resistance, inappropriate rusts, 856

- scald, host calcium relation, S65

- stripe rust, resistance and genetic mapping of genes, S16

- systemic resistance induction, plant activators and Pantoea agglomerans, S10

Barley stripe mosaic virus

—bacterial $r n c 70$ gene, S119

—on barley, pathogenicity gene, S24

Barley yellow dwarf virus

- aphid complex, field resistance in Alabama, S91

-in oat: 17-kDa protein and RNA, localization, 1031; phloem cells, cover photo, October; tolerance, loci, 410; transgenic tolerance, 1013

-PAV serotype variants, distribution in host species, 818

-wheatgrass-derived resistance, wheat alien chromosome substitution line, 851

Barnes, C. W., S6

Bartlett, D. W., S6

Bassi, B., S18

Batista, U. G., S20, 1116

Batten, J. S., S6

Baudoin, A., S128

Bauer, D. W., S134

Baum, N. A., S62

Bauske, E. M., S82

Bautista, M. de J., S121

Bayramian, L. A., S6

Beach, S., S2

Beachy, R. N., 1262, S41, S58, S69, S71, S75

Bean (see also Phaseolus vulgaris)

—nematodes, in Missouri, S22

—root rot, control in Minnesota, S26

Bean calico mosaic virus, characterization, S11

Bean common mosaic virus

—on guar, characteristics, S125

— screening resistance method, S86
Bean golden mosaic virus, resistance, monoclonal antibody evaluation, S122

Bean leafroll virus, detection in aphids, S52

Beattie, G. A., S116

Beaulieu, C., 442

Beaver, J., S121, S122

Becherer, H. E., S12

Becker, C. M., S6, S136

Becker, D. M., S7

Becker, J. O., S7, S42, S83, S96

Beckman, C., 28

Becton, C. M., S77

Beer, S. V., S104, S134

Beet curly top virus, Worland strain, specificity elements, 1174

Beet soilborne mosaic virus, beet necrotic yellow vein virus cross-protection, S57

Beet western yellows virus, component of California carrot motley dwarf complex, RNA, 164

Beet yellow stunt virus, coat protein gene, characterization, 1040

Behe, C. G., S31

Bekal, S., S7

Bélanger, R. R., 396, S99

Bell, A. A., 252, S7, S108

Bell, J., 862

Bell, M. L., S60

Belonolaimus longicaudatus

- on cotton, root growth and yield effect, S19

- host reactions in California, S7

Beltran, J. D., 556, S7

Bemisia spp.

-B. argentifolii, tomato chlorosis virus vector, 402

-B. tabaci: Sinaloa tomato leaf curl virus vector new subgroup, 648; tomato chlorosis virus vector, 402; vector for tomato-infecting geminiviruses, in Puerto Rico, S120

Bender, C., S46, S102, S104

Benhamou, N., 234, 605, S99

Benjama, A., 844

Bennans, T., S82

Bennett, M. A., S99

Benscher, D., S72

Benson, D. M., S13, S42, S124

Bentgrass (see also Agrostis stolonifera and Turfgrass)

-rhizosphere and phylloplane of, Trichoderma ecology, 129

Bentley, S., 30, 1283

Benyagoub, M., 605

Berger, P. H., S34, S59

Berger, R. D., 382, S83

Berner, D. K., 563, S7

Bernier, C. C., S110

Bernier, L., S9, S24, S30, S101

Bertaccini, A., 1359

Berthier-Schaad, Y., S29

Bertrandy, J., 1210

Bessis, R., 472, 740

Best, V. M., S7, S61

Beuselinck, P., S26

Beyer, D. M., S4, S14, S50, S134

Bhat, A. I., S7

Bhat, R. G., S8

Bhattacharyya, M. K., S26

Bianchi, M. L., S91

Biggerstaff, C. M., S8

Bijman, V. P., S64

Biological control

-bacteria: for Erwinia amylovora, inoculum preparation, 506; growth chambers and canopy environmental data, S69

-binucleate Rhizoctonia for Rhizoctonia solani on soybean, 1056

- Candida saitoana for Botrytis cinerea on apple, 282

-Candida sake for blue mold of apple, 960

- compost and water extracts for cucumber and Arabidopsis diseases, 450
- Curvularia tuberculata and C. oryzae on, Cyperaceae weeds, S135

- fungus for soybean cyst nematode, 465

-Fusarium for Erythroxylum coca, 185

-Fusarium culmorum on Hydrilla, 382

-microbial natural products for plant pathogens and insects, S62

-nematode-trapping fungi for Meloidogyne javanica, 344

- Pichia anomala to Botrytis cinerea on apple, 335

- postharvest diseases of apple and pear, Pseudomonas antagonist, $\mathrm{S} 130$

- Pseudomonas fluorescens to tobacco necrosis virus, salicylic acid biosynthetic genes, 678

-rhizobacteria and pathogens on cucumber, 1158

- soilborne diseases, past and next twenty years, S131

-Talaromyces flavus, glucose oxidase localization, 576

- tomato and cherry crown gall, antibiosis, S45

-on tomato and pepper soilborne diseases, Gliocladium and Burkholderia spp., S57

- Trichoderma longibrachiatum to Pythium ultimum, on cucumber, 673

_Ulocladium and Gliocladium for Botrytis cinerea in cyclamen, 568

Bipolaris spp.

-B. maydis: on corn, race $\mathrm{T}$, factors, $\mathrm{S} 7$; on corn, race $\mathrm{T}$ toxin, light and malate effect, 556

-B. sorkiniana: on rice, blast suppression, 735 ; spore sampling platform, helium balloon, S115; on tall fescue, suppression by Stenotrophomonas maltophilia, S119

Bird, J., S42, S120

Black currant reversion virus, synthetic phage display, 230

Blackmon, B. P., S104

Blaich, R., S79

Blank, C. A., S106

Blankenship, J. D., S8

Blastophaga psenes, endosepsis relation, in Calimyrna fig, 637

Blodgett, J. T., 245

Blomquist, C. L., S8

Blowers, A., S83

Blumeria graminis, on wheat, resistance gene, 144

Boch, J., S91

Bock, C. H., S8

Bockelman, H., S85

Bockus, W. W., S110

Bodaghi, S., S8

Boehm, M. J., S30, S47, S118

Bogs, J., 416

Boland, G. J., 788, S33, S93

Bolar, J. P., S8

Bollen, G. J., 764

Bollero, G., S132

Bommarito, S. G., S9

Bonants, P. J. M., 922

Bond, J. P., S9

Bond, W. P., S9

Bonde, M. R., S9, S29, S70, S131

Bonello, P., S9

Borbón, J., 621

Borchardt, D. S., 322

Bordas, A. C., S9

Borek, M., S122

Borovkova, I. G., 76

Boscia, D., 198

Bostock, R. M., S58

Bothast, R. J., S118

Bothner, B., S58

Botrytis cinerea

-on apple: antagonism to, 335; postharvest decay, biocontrol by Candida, 282

-biocontrol, screening system, S57

-conidia, resveratrol oxidation, 472, 740

-on cyclamen, biocontrol with Ulocladium and Gliocladium, 568 
-fungicide and horticultural oil, S64

-on grape, control with carbonate and bicarbonate salts, S64

Bourassa, M., S9

Bourland, F. M., S72

Bouzar, H., 33

Bowen, K. L., S9

Bowers, J. H., S10, S128

Boyd, M. L., 260, S10

Bozarth, R. F., S32

Bracewell, C. R., S10, S124

Brachiaria brizantha, leaf spot and endophytic fungus, S46

Bradley, C. A., S10

Brainard, K. A., S13

Brakke, M. K., 872

Brandl, M. T., 1149

Brassica napus, Leptosphaeria maculans, avirulence locus mapping, 1068

Braun, E. J., 525, S8

Braun, K., S10

Braun, U., S134

Braun-Kiewnick, A., S10

Brayford, D., 30

Bremer, E., S11

Bremia lactucae

- on lettuce, solar radiation effect, S99

- spore release, light initiation and humidity, S86

-sporulation, air and humidity effect, S86

Breuil, C., S30, S38, S47, S94

Breuning, G., S31

Breynia distichia, web blight, new host, S122

Briere, S. C., S11, S86

Briggs, K. G., S65

Briggs, S. P., S65

Brito, J. A., S11

Britz, H., S97

Brlansky, R. H., S54

Brodie, B. B., S11

Broers, L. H. M., S77, S78

Brome mosaic virus, in barley, cell restriction, S22

Brome streak mosaic virus, wheat streak mosaic virus relation, not Rymovirus, 782

Bromoviridae, virus defective movement, in Nicotiana benthamiana, 666

Brown, C. M., 410

Brown, E. W., S129

Brown, G. E., S11

Brown, J. K., 658, S11, S42, S92, S120

Brown, M. W., S43

Brown, R. L., 276, S11, S16, S98

Brown, S. E., S12

Brown, S. K., S8

Browne, G. T., S6, S12, S15

Bruchmüller, I., 416

Bruckart, W. L., S129, S131

Bruton, B. D., 428, S12, S62, S70, S72, S103, S120, S122

Buchanan, R. L., S43

Bucholtz, D. L., 851

Buchwaldt, L., S110

Buck, J. W., S12, S110

Buddenhagen, I. W., 1283

Bukhalid, R. A., S12, S52

Bull, C. T., S9, S109

Bulluck, L. R., III, S12

Buntin, G. D., S91

Burgess, L. W., S135

Burk, J. K., S12

Burkholderia spp.

-B. cepacia, on pea, biocontrol agent, S37

- B. vietnamiensis, biocontrol by, antibiotic production, S46

Burns, J. R., S13, S124

Burpee, L. L., 446, S33, S90

Burr, J. A., S97

Burr, T., S49, S64, S98

Busch, R. H., S56

Bushnell, W. R., S73
Bustamante, E., S13

Butler Carver, L. M., S13, S124

Byrne, A., S30

Byrne, J. M., S134

Cabbage

-clone, putative translation initiation factor, S1

-white mold, wound as predisposing factor, S41

Cacao, microbial ecology, biocontrol potential, S37

Cactodera betulae, cyst nematode relations, DNA, S28

Cadle, M. M., S106

Calderon-Urrea, A. A., S39

Calimyrna (see also Ficus carica)

-caprification and fig endosepsis, cover photo, July

Callahan, A., S131

Callahan, A. M., S77

Callery, M. D., S41

Cambra, M., 198

Cambraia, K. L., S28

Campbell, C. L., S25, S67, S71

Campbell, K. A. G., 1078

Campbell, L. R., 98, S97

Camper, N. D., S70

Camponogara, A., 673

Canaday, C. H., S124

Candida spp.

-C. saitoana, biocontrol agent for Botrytis on apple, postharvest, 282

-C. sake, apple blue mold control, preharvest application, 960

Candresse, T., 198

Cannon, J. M., S17

Canola

-Alternaria black rot, in North Dakota, S112

- disease survey in North Dakota and Minnesota, S52

- Sclerotinia stem rot, in North Dakota, S112

Cappaert, M. R., S106

Capsicum (see Pepper)

Cardenas, J., S13

Carey, D. W., S45

Carey, W. A., S26

Carisse, O., 605

Carling, D. E., 366, S13

Carlson, J. D., S23

Carlton, W. M., 525

Carr, R. V., S130

Carras, M. M., S132

Carris, L. M., 260, S22

Carroll, R. B., S84, S132

Carrot

—aster yellows, preharvest benomyl spray and storage, S117

- motley dwarf complex, beet western yellows virus associated, 164

Carson, M. L., S24, S28

Carsten, L., S4, S13

Carter, D. A., S13

Caruso, F. L., S13

Carvalho, C. M., S13

Carver, T. L. W., S103

Cassava mosaic virus, comparison in Uganda and Ivory Coast, S71

Castañeda, A., S14

Castillo, P., 828

Castlebury, L. A., S19

Castro, J., 306

Catal, M., S110

Catlin, N. J., S14, S134

Cauliflower, Verticillium wilt

— crop rotation and irrigation effect, 1046

- disease management, 1108

Cazorla, F. M., 614

Cecidophyopsis ribis, black currant reversion vector, 230

Celio, G. J., 105, S135

Centaurea solstitialis, seedling pathogens, in California, S98
Cephalosporium spp.

-C. gramineum: on wheat, GUS-transformed strain, S107; on wheat, seed transmission, S106

-C. maydis: on corn, variation in Egypt, S103; pathogenic variation, S25

Ceratocystis polonica, on spruce, bark beetle association, 39

Cercospora spp.

-C. sojina, on soybean, $\mathrm{CO}_{2}$ and infection, $\mathrm{S} 74$

-C. zeae-maydis: on corn, resistance inheritance, 972; on corn, sibling species, 1269

Cercosporella spp., taxonomy, Ramularia and other genera compared to, $\mathrm{S} 134$

Cercosporin

-biodegradation by bacteria, S126

- microbial detoxification, S64

Ceresini, P. C., S14

Cevik, B., S14

Chakraborty, S., S14, S70, S98

Chaloux, P. H., S129

Chambers, M., S11

Chandramohan, S., S15

Chang, C.-J., 1347

Chang, K. F., S94

Changa, C. M., S15

Channa Reddy, C., S74

Chao, C. T., S15

Charest, P. M., 359

Charudattan, R., 382, S15, S80, S83, S88

Chase, T. E., S115

Chatterjee, S. C., S89

Chauhan, R. S., S15

Chellemi, D. O., S63

Chen, B., 598

Chen, C., 1179

Chen, J. (Fla.), S5

Chen, J. (N.Mex.), S109

Chen, L., S41

Chen, S. Y., S16

Chen, T. A., 1367

Chen, W., S62, S115

Chen, W.-Q., 856

Chen, X., S16, S69

Chen, X. M., S16, S81

Chen, Y. D., 1367

Chen, Z.-Y., 276, S11, S16

Cheng, W., S62

Cheng, Z.-M., S35

Chernushevich, I. V., S111

Cherry (see also Prunus spp.)

- postharvest fruit decay, molecular detection, S29

—vessel occlusions, pectin secretion, 494

-western X-disease, outbreak in California, S91

Chesnokova, O. N., S16

Chessin, M., S16

Chestnut

-blight, resistance and chitinase induction, in hybrids, $\mathrm{S} 80$

-ds-RNA, demographic analysis, S20

Chin, C.-K., S94

Chino del tomato virus, molecular characterization, S11

Chiri, A. M., S102

Chittoor, J., S50

Chitwood, D. J., S16

Cho, J. D., S58

Cho, J. J., S46

Cho, W. D., S43

Choi, I.-R., 782, S30, S85

Choi, J. J., S17, S48

Choi, S., S91, S114

Choi, W.-B., 58, S17

Choi, Y. M., S126

Chong, S. K., S56

Chongo, G., S110

Christ, B. J., S54, S55, S74

Christian, D. P., S6

Chu, F.-H., 351 
Chu, F. S., S114

Chun, S.-C., 1255

Chun, W., S17, S72

Chung, S. Y., S12

Churchill, A. C. L., S17

Cicer arietinum

- Ascochyta blight, phenology on debris in Spain, 983

-Fusarium wilt, factors, 1338

-Pratylenchus thornei and Fusarium oxysporum interaction, 828

Cintas, N. A., S17, S106

Circulifer tenellus, Spiroplasma citri vector, symposium, 1351

Citrus

—blight, xylem plugging, S54

-brown spot: environmental factors, 1218; outbreaks in Florida, 724

- canker, gene families, in Xanthomonas, S14

— green mold: carbonate and bicarbonate salts for control, S83; control by syringomycin E, S109

-Phytophthora citrophthora and P. parasitica, seasonal pattern infection in California, S22

-Phytophthora spp. on, root histology, 389

- stubborn disease, detection and yield loss, S69

Citrus tristeza virus

—biolistic inoculation, S38

- citrus aphid relation, infection pattern in Costa Rica and Dominican Republic, 621

- field evaluation in California, S72

-in grapefruit, cross-protection, S73

- management in Texas, S122

-RNA, molecular variability, 685

-RNA polymerase in strains, $\mathrm{S} 14$

- survey methods, 715

Citrus yellow mosaic badnavirus, citrus mealybug vector, S31

Ciuffetti, L., S78

Cladosporium caryigenum, on pecan

-lesion development factors, 1294

-resistance and infection stage, S10

Claflin, L. E., S66

Clark, C. A., 1179, S17, S55

Clark, E., 1149

Clark, M. F., S8

Clark, S. L., S9, S17

Clarke, B. B., S137

Clavibacter michiganensis

—on four-o'clock, hypersensitive response, 306

- genomic fingerprinting, S12

-identification by genomic fingerprinting, 862

-on potato: detection procedure, S52; PCR ELISA detection, $\mathrm{S} 63$

-on tomato: assay, S8; ingress through hydathodes, 525

Claviceps spp., ergot alkaloid biosynthesis genes, Neotyphodium comparison, S133

-C. africana: in sorghum, ergot alkaloid detection, S81; in sorghum, molecular characterization, $\mathrm{S} 132$

$-C$. purpurea: peptide synthetase gene, ergopeptine biosynthesis, S131; on rye, extracellular catalase secretion, role in disease, 744; in rye, $x y-$ lanolyptic system, cytology, 1020; on rye ovary, anticatalase epitopes, cover photo, August

Clement, D. L., S57

Cleveland, T. E., 276, S11, S16, S53, S65, S98

Cloud, G., S18, S124

Coates, S. T., 972

Cochran, A. J., S115

Coconut

—red ring disease, survey in Puerto Rico, S122

- Tinangaja, detection by RNA extraction and electrophoresis, S123

-tinangaja viroid: detection, S93; field diagnosis in palm, 774

Coddington, A., 30

Coffee ringspot virus, new Brazilian isolates, S13

Coffeen, W. C., S18
Cohen, M., S73

Colas, V., 205

Colburn, G. C., S18

Colletotrichum spp.: on citrus, allozyme analysis, S104; on postharvest fruits in Brazil, molecular studies, S70

- C. acutatum: conidia, splash dispersal and cover crop effect, 536; genetic marker, segregation, S34

-C. gloeosporioides: on anemone and strawberry, comparison, S29; on Stylosanthes scabra, race frequency, S14; on yam, glycoproteins, S120

-C. graminicola, on sorghum, genetic structure, 1087

-C. lindemuthianum: on bean, induced resistance, 359; on bean, Mexican isolate characterization, 292

-C. orbiculare, on cucumber, systemic acquired resistance, 450

Collins, D. P., S18

Collins, N., S41, S87, S95

Colocasia esculenta, leaf blight

- evaluation in Hawaii, S46

-resistance evaluation, S123

Colón-Garay, J., S120

Competition, interaction analysis, de Wit models, letter to editor, 873

Compost, resistance induced by, specificity, S49

Condon, J. M., 70

Conifer, needle fungi, DNA oligonucleotide probes for detection, S110

Conn, K., S52

Conway, W. S., S18, S43

Cook, D. D., S62

Cook, D. L., S85

Cook, M. J., S18

Cook, R. J., S80

Cooksey, D. A., S52, S76

Cooper, B., 666

Copes, W. E., S125

Coplin, D. L., S18, S36

Corn

-aflatoxin production, planting date and harvest moisture effect, $\mathrm{S} 90$

-Aspergillus flavus: on kernels, protein association, 276; localization in ears, S98

-Bipolaris maydis, race $\mathrm{T}$ toxin, light and malate effect, 556

- Cochliobolus carbonum race 1 , molecular basis, S65

—defoliation, yield effect, S2

-Fusarium spp., fumonisin production, $\mathrm{S} 112$

- genetic variation in germplasm, RAPD-PCR markers, aflatoxin, S53

— glossy mutants, bacterial colonization, S116

- gray leaf development, narrow rows, S132

- gray leaf spot: disease severity using computers, S117; fungicides, S116; photosynthetic stress-translocation balance concept, S113; resistance inheritance, 972; sibling species of $\mathrm{Cer}$ cospora, 1269

-kernel epicuticular wax, antifungal components in, S32

—-kernel rot, lambsquarter density effect, S84

- leaf positions yield and disease severity, S118

- moniliformin screening, TLC method, S92

-northern leaf blight, tropical and temperate climates, 322

- pathogen detection by analysis of ITS regions, S24

-residue-borne diseases, epidemiology, S112

-root rot, Pythiogeton in Korea, S43

-rust, resistance and loci mapping, 1324

-rust resistance, recombination and structural diversity, S41

—rust resistance locus, allelic diversity, S87

- southern rootworm, vector for rhizobacteria, 1248

—stalk residue, Fusarium spp. survival, 550

- Stewart's disease: monthly temperature relation, in Iowa, S113; site-specific forecasts, S68
- Stewart's wilt, southern rust, and smut, resistance, $\mathrm{S} 70$

Cornus spp., powdery mildew, cleistothecial role in Tennessee, S64

-C. florida, powdery mildew, fungicides, S22

Correa, F., S80, S126

Correll, J. C., 30, 465, S19, S34, S55, S126

Corr-Mainini, C., S39

Cortés Castro, M., S120

Cortês, I., 1276

Cortés, M., S122

Cortesi, P., S54

Corylus avellana, blight, ascospore release factors, 122,1165

Cotten, T. K., 550

Cotton

-Agrobacterium wilt and bronzing, nutrition effect, S7

-angular leaf spot, water soaking, S14

-Aspergillus flavus, enzymes and invasive ability, S11

—bacterial blight, gene mapping and resistance, S99

-bacterial endophytes in cultivars, genotype effect, S2

-rhizosphere, bacterial community, herbicidetreated soil, S37

-root-knot nematode and black root rot comparison, temperature effect, $\mathrm{S} 92$

- seedling disease management, in Louisiana, S61

Cottonwood, insects and diseases, softwares for rapid recognition, $\mathrm{S} 97$

Cotty, P. J., S8, S10

Cover photo

-Arabidopsis thaliana, Ralstonia solanacearum on leaves of, April

- barley yellow dwarf virus, in oat, October

- Calimyrna fig, caprification and fig endosepsis, July

-Claviceps purpurea, on rye, anticatalase epitopes, August

-Erwinia amylovora on apple, May

-iris yellow spot virus on plant, December

-Oidium sp., on poinsettia, conidial germination, February

- peanut stunt virus, on tobacco protoplasts, November

-Prunus pensylvanica, stained tree sections, Ophiostoma ulmi, June

- Striga asiatica, on sorghum, radicle effects in haustorium, January

- tobacco ringspot virus, in Xiphinema americanum, September

- tomato Pythium infection, March

Cowger, C., S19

Cowpea mottle virus, in Vigna, detection method, S32

Cox, R. M., S49

Coyne, D. P., 730

Cranberry, fruit rot fungi, distribution in Massachusetts, S77

Craven, K. D., S19

Creamer, R., S69

Creswell, T. C., S39

Crippen, D. L., S89

Cronartium spp.

- C. quercuum, on slash pine, spatial and temporal stability, S33

-C. ribicola: genetic structure, 1187; urediniospores, DNA extraction, S102; on white pine, genetic structure in populations, 1187

Crop residue, stubble-borne pathogens, control tactics, S110

Crosslin, J. M., S36

Crow, W. T., S19

Crowe, F., S19, S89

Cryphonectria parasitica

- on chestnut, RNA occurrence in China and Japan, 811 
- growth and sporulation, hypovirus recovery site, S129

- hydrophobin cryparin, virus effect, S59

-hypovirulent strain, hypovirus transmission, 598

- vegetative compatibility genes, hypoviruses in strains of chestnut, S128

- vegetative compatibility groups, hypoviruses, S54

-virus-fungus interaction, S54

Cubeta, M. A., S14, S41

Cucumber

—anthracnose, systemic acquired resistance, 450

- foliar pathogens, ecological association in North Carolina, S71

- leaf spot, incidence in North Carolina, S25

- pathogens and rhizobacteria, mixtures in biological control, 1158

-phytoalexins, flavonoid, silicon-mediated, 396

-Pythium ultimum, biocontrol with Trichoderma, 673

Cucumber mosaic virus

- aphid transmission phenotype, S67

-on pepper, weed hosts, S38

-replicase-mediated resistance, subgroup, S98

—on Salvia uliginosa, S39

— satellite RNA, helper virus, 520

-on tomato, replicase mediated, 1101

-WL1 satellite RNA sequence, S52

Cucurbit

— gummy stem blight, sequence analysis, S83

-Phytophthora fruit rot, cultural practice effect, S60

- powdery mildew, herbarium speciment use, S136

-yellow vine disease, bacterium-like organism, detection, 428

Cucurbita maxima, coumaryl aldehyde from, antifungal, S84

Cuda, J. P., S80

Culbreath, A. K., S33, S127

Cunfer, B. M., S19, S91

Cuppels, D. A., 1094

Curry, K. J., S126

Curtis, M. J., S20

Cvijetkovic, B., S45

Cyathus olla, ligninolytic enzyme system, S82

Cyclamen

-Fusarium wilt, suppression with $\mathrm{NaCl}, \mathrm{S} 135$

-leaf rot, biocontrol with Ulocladium and Gliocladium, 568

Cynoglossum officinale, bacteria and herbicide effect, $\mathrm{S} 104$

Czapla, T. H., S75

Czosnek, H., 910

Daayf, F., S20

Daboussi, M.-J., 30

Dahal, G., S20

Dallot, S., 198

Dally, E. L., S20, S129

Damann, K. E., S32, S53

Damicone, J. P., S104

Damrongkool, P., S131

Damsteegt, V., S130, S131, S133

D'Arcy, C. J., 1031, S38

Datnoff, L., S80, S126

Daub, M. E., S64, S126

Daughtrey, M., S135

Davelos, A. L., S20, S43

Davies, D. L., S8

Davies, J. S., S11

Davis, J. R., S107

Davis, K. R., 450

Davis, M. J., S20

Davis, R. D., 1283

Davis, R. E., 1372, S20, S80, S129

Davis, R. M., 252, S2, S129

Dawson, W. O., 1040, S46

Deahl, K. L., 939, S129

Dealessi, L., 673

Dean, R. A., S17, S32, S83, S95, S104 de Bruijn, F. J., 862, S61

de Capdeville, G., 1116, S20, S21

DeCeuster, T. J. J., S49

de Cock, A. W. A. M., 213, 922

Défago, G., 678, S23

de Groot, K. E., 1315

De Haas, B. H., 568

de Kochko, A., S41, S58, S69

De La Torre, R., S21, S55

Delauney, A., S120

Delgado, J., 306

del Rio, L., S21, S110, S115

De Luna, L. Z., S135

Demezas, D., S104

de Nazareno, N. R. X., S112

Dendroctonus rufipennis, on Engelmann spruce, gene relation, $\mathrm{S} 5$

de Neergaard, E., 698

DeNoma, J. S., S72

Deom, C. M., 666

Derks, A., 1276

Dery, P. D., S76

Descalzo, R. C., S21

Desilets, H., S102

Desjardins, A. E., S73

Dessens, J. T., 818

Desurmont, C., 1149

Desvoyes, B., S21, S70

de Tomasel, C. M., S107

de Vicente, A., 614

De Wolf, E. D., S21, S29, S115

de Zoeten, G. A., S82

Diabrotica undecimpunctata, Pseudomonas chlororaphis vector, in corn, 1248

Diagnosis

- communication and public relations, S117

—-digital, in practice, S39

-Oklahoma Plant Doctor and Internet, S41

—web site for plants, landscapes, and pests, S57

Diaporthe phaseolorum, on soybean, molecular identification, 1306

Díaz, E., S120

Dick, W. A., 450

Dickman, M. B., S76

Dickson, D. W., S11, S19, S76

Dickstein, E. R., S67

Didymella spp.

-D. bryoniae, on cantaloupe, fungicides, S62

-D. rabiei, on chickpea, phenology on debris in Spain, 983

Dileone, J. A., S35, S45, S57

Dill, M. A., S78

Dill-Macky, R., S27, S56

Dinesh-Kumar, S. P., 1013

Ding, X., S22

Ding, X. S., S22, S40

Dirac, M. F., S22

Disease

- diagnosis with digital images, in Wyoming, S11

-new and emerging, status and projection, S132

Dissanayake, N., 530

Ditylenchus dipsaci, distribution in Colorado, $\mathrm{S} 107$

Doan, M. C., S22

Dodd, J. L., S113

Dodder, Colletotrichum pathogenic to, S13

Dodds, J. A., 514, S8

Dodo, H. W., S73

Domier, L. L., 410, 1031

Donald, P. A., S22

Doney, J. C., S22

Dorfmüller, S., 63

Dorrance, A. E., S22

Doster, M. A., S23

Doucett, K., 265

Douds, D., Jr., S66

Douhan, G. W., S107

Douhan, L. I., S23

Drake, J., S87

Drayton, M. N., S62
Drechslera teres, on barley, induced resistance mechanism, 698

Driever, G. F., S23

Dripps, J. E., S79

Drouillard, D. L., 724

Duan, Y. P., S14, S23, S122

Dubey, T., S23

Ducharme, D. T., S23

Duffus, J. E., 402, 1040, S54

Duffy, B. K., S23

Dufour, J., S24

Duncan, R. R., 1087

Dunez, J., 198

Duniway, J. M., S36, S100

Dunkle, L. D., 1269, S17, S24

Dusabenyagasani, M., 1187, S24

Duthie, J. A., S23, S24, S104

du Toit, L. J., S24, S70

Dyer, A. T., S24

Dysmicoccus spp., pineapple mealybug wilt vector, 1224

Dyson, T., S39

Eager, T. J., S4

Eastburn, D. M., S38

Ebbole, D. J., S33

Echávez-Badel, R., S121

Echinacea spp., Sclerotinia, fungicides, S94

Echt, C. S., S102

Edelson, J. V., S24

Edwards, M. C., S24

Effertz, R. J., S24, S25

Egel, D. S., S25

Eggenberger, A. L., S25, S118

Egley, G. H., S1

Eichhornia crassipes, Cercospora spp. on, molecular characterization, S88

Eipremnum aureum, Phytophthora tropicalis, new disease, $\mathrm{S} 45$

Eisenreich, R., S83

Eising, R., 744

El-Abedein, A. Z., S25

El-Allaf, S. M., S25

Elaphomyces granulatus, mammal foraging pattern relation, $\mathrm{S} 6$

El-Assiuty, E. M., S25, S103

El-Dakak, A., S25

Elderberry latent virus, genome organization, S48

El-Ghaouth, A., 282

Elias, K., 30

ElKaffash, W. M., S25

Elkins, R., 1149

El-Leithy, S., S75

Ellis, J., S41, S87, S95

Ellis, M. A., 536, S26

Elm

- propiconazole residence in wood, determination, S128

— 'Valley Forge' cultivar in Dutch elm disease, S45

—vessel occlusions, pectin secretion, 494

Elmer, W. H., S135

El-Morsy, G., 33

El-Shafey, H. A., S25, S103

Elson, M. K., S129

El-Zik, K. M., S99

Emele, L. R., S25

Emery, K. M., S26

Empoasca fabae, on bean, chitinase gene and protein induction, S40

Endophyte, on grass, protective alkaloid expression, S8

Enebak, S. A., S3, S26

English, J. T., S26

English-Loeb, G., S30

Ens, W., S111

Enterobacter cloacae, mutant use in biocontrol, S76

Enterolobium cyclocarpum, decline in Mexico, S88

Epidemics, crop-weed interaction, theory, letter to editor, 180 
Epidemiology

—neural network, utility, S29

- spatio-temporal dynamics, factors, letter to editor, 1000

Erbar, C., 416

Erdos, G., S23

Erickson, E. O., S97

Erickson, F. L., S39

Erincik, O., S26

Errata

—vol. 87 , no. $6,628,740$

-vol. 88 , no. $1,52,272$

- vol. 88 , no. $5,472,740$

—vol. 88, no. 9 (Suppl.), 1116

Erwinia, taxonomy, necrotic and soft-rotting species, S129

Erwinia sp., in tree sap, detection with ELISA, S60

-E. amylovora: on apple, colonization, 416; on apple leaf hairs, cover photo, May; enterobacterial GAPDH gene, analysis, S129; harpin, functional domain, S67; on pear and apple, antagonism factors, 506; streptomycin resistance, apple and pear management, S61

- E. chrysanthemi, galacturonic acid transport, role of ExuR, S91

$-E$. herbicola, host specificity, gene interactions, S6

Erythroxylum coca, Fusarium wilt

-ant dispersal, 185

-factors, 544

Escherichia coli, on apple, growth and insect transmission, $\mathrm{S} 43$

Eshel, A., S27

Eshita, S. M., S45

Esnard, J., S26

Espinosa, B. G., S26

Estabrook, E., 164

Estevez de Jensen, C., S26

Et-touil, K., 1187

Eun, J.-C., S27

Euonymus fortunei, anthracnose, fungicide resistance, S51

Euphorbia heterophylla, powdery mildew, susceptibility, S135

Evans, C. K., S27

Evans, N., S27

Everts, K. L., S27, S130

Exserohilum turcicum, on corn, population structure, S28

Extracts

- antifungal proteins, purification, S40

-tropical plant, antifungal activities, S39

Eyal, Z., S27

Ezra, D., S6

Ezrati, S., S27

Faba bean necrotic yellows virus, aphid transmission, molecular determinants, S29

Faghihi, J., S28

Fahmy, Z. M., S25

Fahnert, M. L., S27

Faivre-Rampant, P., 156

Fajardo, J. E., S27

Fakhoury, A. M., S28

Falk, B. W., 164

Fan, H., S67, S87

Fang, E., S17

Farman, M. L., S15

Farré, J. M., 614

Fauquet, C., 1262, S41, S58, S69, S71

Faure, J.-E., 1101

Fawe, A., 396

Fay, L. D., S101

Febres, V. J., S14

Feliciano, A. J., S28

Felts, D., S27

Fenille, R. C., S50

Fenn, P., S28
Ferguson, L. M., S28

Fernandes, C. D., S14

Fernandez, D., 30

Fernandez, G. E., S13, S124

Ferrandino, F. J., 84, 490

Ferreira, S. A., S31

Ferris, H., 344

Ferris, J. M., S28

Ferris, V. R., S28

Fery, R. L., S89

Festuca arundinacea, endophyte phylogeny, S19

Fetch, T. G., Jr., S28, S85

Ficus carica (see also Calimyrna)

—endosepsis, spread in orchards, 637

Figueira, A. R., S13, S28, S64, S68

Filho, E. R., S113

Finger, F. L., 1116, S20

Fischer, W., S37

Fisher, G. A., S107

Fisher, K. H., S95

Flanagan, S., S60

Flasinski, S., S5, S22

Fletcher, J., 428, 1351, S75, S80, S95, S102

Flores, H. E., S133

Flores, R., 685

Fogle, D., S98

Foglia, R., 811, S54

Foot-and-mouth disease virus, protease in transgenic tobacco, multiple genes, S56

Forbes, G. A., 265

Ford, R. E., 480

Forest, diseases and canopy gap, S56

Forrer, P. D., S60

Förster, H., S29, S107

Forster, R. L., S86

Forster, R. L. S., 311, S95

Fraile, A., 520

Franc, G. D., S11, S29, S86, S108

Francki, M. G., 851

Francl, L. J., S21, S24, S25, S29, S30, S62, S114, S115

Frank, J. R., S29

Frankliniella occidentalis, on tomato

—protein binding by virus, 63

- protein interaction with tomato spotted wilt virus, 98

Frantzen, J., 180

Franz, A. W. E., S29

Fratamico, P., S43

Fravel, D. R., 185, 544, 576, S51, S130

Frederick, R. D., S9, S29, S70

Frederiksen, R. A., 1087

Freeman, S., S29

Freeman, T. P., 1056, S34

French, R., 782, S30, S85

Friebertshauser, G., S83

Friesen, T., S30, S115

Frohberg, R. C., S84, S116

Fry, W. E., 837, 939, S34, S59

Fukui, R., S30

Fulbright, D. W., 862, S128

Fungicides (general)

-BLITECAST and TOM-CAST comparison, in Mexico, S34

-Botrytis cinerea on strawberry, S13

-Doppler particle analyzer, splash droplet characterization, S68

- foliar disease, doses and number of applications, S104

—potato late blight, coordination of trials, S107

-registration update from IR-4, S89

Fungicides (specific)

-benomyl, for citrus postbloom fruit drop, S84

-ELEVATE, Botrytis and monilinia control in strawberry, grape, almond, and stone fruits, S3

-ELEVATE/DECREE: Botrytis and Monilinia control, S79; for Botrytis cinerea and Monilinia, $\mathrm{S} 136$

—fludioxonil: broad spectrum seed treatment, S103; seed treatment for crop plants, $\mathrm{S} 81$

-strobilurin, from Novartis Crop Protection, S88

- tebuconazole, postharvest diseases of citrus, in Florida, S11

-trifloxystrobin: for apple and grape, S51; behavior and plant effect, S37; on peanut, cucurbits, and vegetables, S18

- triticonazole, seed treatment for cereal bunts and smuts, S48

Fusarium spp.: biocontrol by systemic resistance induction, S130; on Calimyrna fig, endosepsis, 637; in corn fields and grain, biodiversity of species, S32; corn stalk residue, survival, 550; macroconidial differentiation, computer-assisted shape analysis, S79; on soybean, in Argentina, $\mathrm{S} 30$

-F. culmorum: deoxynivalenol and nivalenol, in rye, 879; spore dispersal, aquatic systems, 382

-F. graminearum: on wheat, variation in North Carolina, S93; on wheat, variation sources in screening nurseries, 1078

-F. moniliforme: benzoxazinoids, detoxification by, S32; fumonisin B1 biosynthesis, nitrogen concentration, S81; fumonisin biosynthesis, mutant, S81

-F. oxysporum: on asparagus, in Washington, S22; on banana, vegetative compatibility group, genetic variation, 1283; Cannabis sp. controlled by, S89; on chickpea, factors, 1338; on Erythroxylum coca, dispersal by ants, 185 ; on muskmelon, Japanese strains and variation, 804; parasitic relation to Melanospora sp., S36; Pratylenchus thornei interaction on chickpea, 828; sporulation, factors, 544; on sugar beet, soil fumigants, S107; on tomato, population genetics and microevolution, S77; on tomato, temporal and spatial spread, S75; on tomato and muskmelon, biocontrol with nonpathogens, S51; vegetative compatibility groups, systematic numbering, 30

- F. proliferatum, on asparagus, vegetative compatibility groups, S135

-F. sambucinum: on potato, induced resistance, $\mathrm{S} 34$; thiabendazole resistance, synthetic peptides, S33

-F. solani: on coca, control agent, S1; on kidney bean, chlamydospore factors, 148; on soybean, herbicide effect, S113; on soybean, molecular comparisons to other isolates, S53

-F. subglutinans: on conifers, susceptibility in 11 species, S17; on longleaf pine, seed treatment, S3; outcrossing in California, S97

Gabriel, D. W., S14, S23

Gadoury, D. M., 902, S25, S30, S79, S83

Gaeumannomyces graminis, pathogenicity genes,

DNA analysis, S74

Gagné, P., S30, S101

Gallegly, M. E., S129

Gallenberg, D., S111

Gallo-Meagher, M., S1

Gally, T., S30, S32

Gal-On, A., 1101

Gang, G., 879

Garcia, S., S75

García-Arenal, F., 520

Garcia-Jimenez, J., S72

Gardan, L., 844

Garling, D. C., S30

Garnsey, S. M., 621, S31, S38, S46

Garraway, M. O., 556, S7

Garre, V., 744

Garrido-Ramirez, E. R., S81

Garry, C. E., S88

Gaskill, D. A., S31

Gates, R. N., S97

Gay, P. A., S31, S73

Ge, X., S3

Geary, B., S31 
Geere, I. W., S21

Geider, K., 416

Geiger, H. H., 322, 879

Geiger, J. P., 1141

Geletka, L. M., 598

Geminiviruses, distribution and diversity, Trinidad and Tobago, 1262

Gene

- gene-for-gene coevolution, system stability, letter to editor, 592

— promoter in plant, pathogen activation, S43

- silencing, viral suppressor, in plants, S3

George, M. L. C., 223

Gergerich, R. C., 885, S94, S127

Gerhardt, S. A., 456, S49

Gerik, J. S., S107

Gerlagh, M., 568

German, T. L., S61, S64

Ghabrial, S. A., 92, 1192, S31

Gianfagna, T., S94

Gibb, K. S., S68

Gibberella spp.

- G. fujikuroi, mating population, fumonisin and genetic complementation, S173

-G. zeae: ascospores, mass production, $\mathrm{S} 44$; on wheat, ascospore development and discharge, S4

Giblin-Davis, R. M., S11

Gibson, P. T., S56

Giesbert, S., 1020

Giesler, L., S69, S102

Gigaspora gigantea, on carrot, signaling and recognition events, S66

Gignac, M., S30, S101

Gilbert, R. D., S32

Gilbertson, R. L., S6, S44, S73, S81

Gilchrist, D. G., S58

Giles, C. G., S79

Gill, R., S32

Gillaspie, A. G., Jr., S32, S125

Gillespie, T. J., S93

Gillette, K. S., S32

Gisi, U., S37

Gitaitis, R. D., S92

Glass, N. L., S58

Glazener, J. A., S130

Gleason, M. L., 525, S8

Glenn, A. E., S32

Glickmann, E., S76

Gliocladium roseum, biocontrol agent for Botrytis on cyclamen, 568

Globodera spp., separation by host, S126

Goeke, S. C., S58

Goeke-Clifton, S., S126

Goh, Y.-K., S32

Goldbach, R. W., 63, S39

Goley, E. D., S130

Golino, D. A., 1231, S32

Gomez, A., S21

Gonsalves, C., S34

Gonsalves, D., S31, S34, S49, S84, S137

González, B., S30, S32

Gonzalez, C. F., S33

González, M., 292

Gonzalez, M. S., S121

González-Candelas, L., 673

Goodman, R. M., S83

Goodwin, S. B., 939, S33

Goos, R., 28

Gorbet, D. W., S33

Gordon, D. T., S15, S75

Gordon, T. R., 30, S9, S17, S85, S86, S97

Gorris, M. T., 198

Gort, G., 1131

Goth, R. W., S33

Gottwald, T. R., 621, 715, 1218

Goué-Mourier, M. C., 156

Govers, F., 754, 1315

Goyer, C., 442
Gracia-Garza, J. A., 185, 544, S33

Grafton, K., S26, S114

Grafton-Cardwell, B., S72

Graham, J. H., 389, 724

Gramacho, K. P., S33

Grape

- Agrobacterium vitis, detection by PCR, S64

-black rot: control period, S25; wet period effect, S128

—canopy, surface wetness, S57

- closteroviruses, transmission by mealybugs, S32

-decline: in California, S78; Phaeoacremonium spp., $\mathrm{S} 108$

—disease reduction by canopy management, S95

- downy mildew, disease severity using computers, S117

-Eutypa dieback, fungicide screening, S76

-leafroll-associated viruses 4 and 5, partial sequencing and assays, 1238

-leafroll disease, associated viruses 4 and 5, partial sequencing and RT-PCR assays, 1238

-measles, etiology in California, S91

-Phytophthora and Pythium, in California, S6

- powdery mildew: and Botrytis bunch rot, petroleum oil effect, $\mathrm{S} 67$; bud perennation in California, S74; cleistothecia as inoculum in Germany, S79; suppression by mite, $\mathrm{S} 30$

-rupestris stem-pitting disease: virus association and nucleotide sequence, 1231; virus detection, 1231

-transgenic rootstocks, grapevine fanleaf and grapevine leafroll viruses, S49

- virus elimination, tissue culture protocol, S32

-yellows, in Virginia, subgroups, S129

Grapevine virus A, on peppermint and spearmint, stunting syndrome, S89

Grau, C. R., S52, S64, S111, S114, S115, S116

Graves, W. R., S61, S122

Gray, F. A., S39, S107

Gray, L. E., S115

Gray, S. M., 851

Green, D. E., II, S33

Greene, A. E., 851

Greenough, D. R., S9

Gremmeniella abietina, on conifers, European race introduced to North America, 582

Greyerbiehl, J. A., S34

Grice, B. A., S117

Grief, R. A., 795

Griffin, J. L., 530

Griffiths, H. M., S38

Gross, D. C., S79

Gross, P. L., S34, S111, S114, S115

Groth, J. V., S6

Grundler, J., S22

Grünwald, N. J., S34

Grybauskas, A., S132

Grzegorczyk, W., S32

Guan, J., S111, S115

Guaragna, M. A., S48

Gubba, A., S34

Gubler, W. D., S9, S28, S63, S74, S76, S78, S91, S108

Gudmestad, N. C., S77, S117

Guerber, C. A., S125

Guerber, J. C., S34

Guerri, J., 685

Guest, C. A., S118

Guignardia bidwelliii, on grape, infection requirements, S68

Guikema, J., S38, S60, S77

Guilhabert, M. R., S83

Guiltinan, M. J., S37

Gulya, T. J., S34, S116

Gundersen-Rindal, D. E., 1359

Gunner, H. B., S135

Guo, B. Z., 276, S53

Guo, L., S63

Guo, Y. H., S35, S93
Guo, Z. T., S84

Gusse, J. F., S11

Gutierrez, W. A., S35

Guy, P. L., S95

Guzman, P., S44, S81

Gyenis, L., S35

Ha, Y., S59

Haas, D., 678

Haber, S., S111

Hacker, J. K., S68

Hadidi, A., S66

Hadwiger, L. A., S17, S48

Hafez, S., S3

Hagen, M. J., S85

Hagler, W. M., S93

Hakes, H. R., S35

Haley, S. D., S112

Hall, F. R., S68

Hall, J. S., 782, S85

Hall, L., S111

Hall, M. H., S136

Hall, R., S95

Hall, R. B., S118

Hall, T. W., S35

Halloin, J. M., S35, S44

Halsey, M. E., S35

Hamelin, R. C., 582, 1187, S9, S67

Hamlen, R. A., S132

Hamm, P. B., 190

Hammerschmidt, R., S34, S89

Hammond, J., 965, S35

Hammond, R. W., S36, S103

Han, D. Y., 450, S36, S49

Hanan, J. S., S98

Handelsman, J., S83

Hansen, J., S59

Hanson, L. E., S36, S40

Hao, J. J., S36

Harbaugh, B. K., S121

Harikrishnan, R., S36, S111

Harlton, C. E., 213

Harman, G. E., 129, S8

Harp, T. L., S19

Harpin

-environmental effect on degradation, S69

-HR elicitor, defense and growth systems effect, S96

-insect control, S104

Harrell, M. O., S93

Harri, J. A., S68

Harrington, T., S87

Hart, L. P., S40

Hart, S. E., S10

Hartin, R. J., S107

Hartman, G. L., 1306, S10, S53, S57, S65

Hartman, J. R., S22

Hartzler, R., S78

Hartzog, C., S36, S107

Harveson, R. M., S36

Harvey, T. L., S80

Hasey, J., S84

Hatziloukas, E., S84

Hau, B., 1338

Haubsbeck, M. K., 862

Haugen, L. M., S37

Hausbeck, M. K., 105, S134

Hayashi, N., 822

Hayes, C. K., 129

Hayes, P. M., S16

Haynes, J. L., S72

Haynes, K. G., S54, S55, S74

$\mathrm{He}$, S. Y., S40

Heald, T. E., S39

Healy, F. G., S12

Hebbar, K. P., S37

Hebbar, P. K., 185, S57

Heckrodt, W., S117

Hedrick Oelke, L. M., S112 
Heeb, S., 678

Heidel, G. B., S37

Heimann, M. F., S116

Heist, E. P., S37, S130

Helgeson, J. P., S51

Helminthosporium solani, conidiation, carbon and amino acid effects, S129

Hendson, M., S83

Henkels, M. D., S37

Herbicide, sugarcane growth and Pythium root rot effect, 530

Herlache, T. C., S64

Hermann, D., S37

Hernandez, A., S88

Hernández, F., 292

Hernandez-Tejeda, T., S3

Heterobasidion annosum, on conifers, history and management, S76

Heterodera spp.

- H. glycines: control, races, 465 ; on soybean, sup pression with chitin degrading bacteria, S89

-H. schachtii: soil suppressiveness, establishment, S96; on sugar beet, soil fumigants, S107

- H. trifolii, on white clover, induced resistance, S46

Heungens, K. K., S37

Hevea brasiliensis, vessel occlusions, pectin secretion, 494

Heydari, A., S37

Hibino, H., S66, S69

Hickey, K. D., S130

Hiebert, E., S82, S122

Higgins, B., S85

Hilaire, E., S38, S77

Hilf, M. E., S31, S38

Hill, C. B., S71

Hill, G. T., S38

Hill, J. H., 895, S25, S118

Hill, J. P., S36, S107

Hillman, B. I., 811, S54

Hirata, H., S82

Hiremath, S. T., S38, S47

Ho, G.-D., 330

Ho, H. H., S43

Hoagland, R. E., S38

Hobbs, H. A., S38

Hodgson, R. A. J., 774, S93

Hoffman, B., S38

Hoffman, D., S22

Hogenhout, S. A., S39

Hogg, D. B., S52

Hohne, R. J., S4

Hoitink, H. A. J., 450, S3, S36, S49, S63

Holcomb, G. E., S39

Holland, J. B., S82

Hollingsworth, C. R., S39

Holmes, G. J., S39, S121

Holzberg, S. P., S39

Homeyer, C. A., S67

Hong, C. X., S39

Hood, M. E., 70

Hoogkamp, T. J. H., 856

Hoover, R. J., S50

Hopkins, M. S., S125

Hoplolaimus columbus, on alfalfa and soybean, reproduction on root culture, $\mathrm{S} 87$

Hossain, T. R., S39, S40

Hou, R. F., S54

Hou, Y.-M. (Calif.), S44, S81

Hou, Y.-M. (Okla.), S40

Houseworth, D., S2

Howard, R. J., S94

Howell, C. R., S12, S36, S40

Howell, W. E., S36

Hoy, J. W., 530, S9

Hoy, M. W., S17

Hoyos, M. E., S40

Hsu, H. T., S40
Hu, C.-C., 92, S31

Hu, J. S., 1224, S40, S80

Hu, S., S34

$\mathrm{Hu}, \mathrm{W} ., \mathrm{S} 40$

Huang, H. C., S11

Huang, Q., S41

Hubbard, J. C., S41, S81, S86

Huber, D. H., S128

Huber, D. M., S35, S113, S118

Hudgins, E. J., S41

Hudyncia, J., S41

Huerta-Espino, J., 890, S82

Huet, H., S41, S69

Hughes, C., 715

Hui, Y., S113

Huisman, O. C., S81, S107

Hulbert, S., S4, S41, S87, S95, S96

Humulus sp., virus incidence, core collection, S72

-H. lupulus, latent viroid, in Washington, S108

Hunger, R. M., S42

Hunter, W. B., S122

Hussey, R. S., S22

Hutchinson, C. M., S42

Huynh, B., S42

Hwang, J., S42

Hwang, S. F., S94

Hyakumachi, M., 148

Hydrilla verticillata

_biocontrol with Fusarium culmorum, 382

- control with fungal and insect biocontrol agents, S80

Hynes, R. K., S11

Hypersensitivity

- Clavibacter michiganensis on Mirabilis jalapa, 306

—expression in bean, S42

Ibañez, A. M., 1218

Ibbotson-Darhower, H., S130

Icard, A. H., S63

Idris, A. M., 648, S11, S42, S92

Iezzoni, A., 376

Ilarraz, E. S., S13, S68

Ilieva, E., 922

Imbe, T., 822

Inglis, D. A., S107

Inoculation technique, fungal pathogenicity, quantitative, S100

Ips typographus, on spruce, blue-stain association, 39

Iris yellow spot virus, new species: molecular characterization, 1276; plant infection, cover photo, December

Irish, B. M., S19

Isakeit, T., S34, S62, S103, S122, S123

Ishimaru, C. A., 862, S12

Ismael, A.-S., S25

Ivors, K. L., 122, 1165, S42, S108

Izioka, H., S50

Jabaji-Hare, S. H., 359

Jackson, M. A., S129

Jackson, T. A., S42, S125

Jacobi, W. R., S93

Jacobo, J. L., 292

Jacobsen, B. J., S2, S10, S18, S47, S104

Jacquot, E., S58

Jaffee, B. A., 344

Jaime-Garcia, R., S43

Jain, L., 1210

Jain, R. K., S7, S125

Jakobek, J. L., S42, S43

Jakstys, B. P., 1031

James, D., S43

James, R. V., S23

Janisiewicz, W. J., S18, S43, S130

Janssen, G. J. W., 658

Janssen, R., 658

Jardine, D. J., S112
Järlfors, U. E., 1192, S31

Jarosz, A. M., S20, S43

Jarret, R., S5

Jasalavich, C. A., S43

Jeandet, P., 472, 740

Jedryczka, M., 1210

Jee, H. J., S43

Jeffers, S. N., S23, S44

Jeger, M. J., 481

Jellison, J., S43

Jeong, J. S., S68

Ji, C., S44

Ji, P., S44

Jiang, H., S44

Jijakli, M. H., 335

Jiménez-Díaz, R. M., 828, 983, 1338

Jin, H., 410

Jin, Y., 76, S28, S44

Johal, G. S., S40, S65

Johansen-Naime, R. M., S68

Johnson, B. J., S1

Johnson, C. S., S44

Johnson, D. A., 190, S23, S31

Johnson, D. J., S44

Johnson, J., S132

Johnson, J. J., S91

Johnson, K. B., 122, 506, S45, S78, S108

Johnson, L. B., S101

Johnson, T. E., S45

Johnston, M. R., S13

Jolley, L. W., S45

Jomantiene, R., S129

Jones, A., S40

Jones, J. B., 33, S63, S90

Jones, S. S., S106

Joppa, L. R., S118

Jordahl, J., S24, S25, S30

Jordan, R., S46, S48, S58

Jørgensen, H. J. L., 698, 735

Jung, G., S85

Jurgenson, J. J., S103

Jurjevic, Z., S45

Kado, C. I., S16, S51, S73

Kadooka, C. Y., S45, S90

Kalieva, G. T., S4

Kalloger, S., S59, S80

Kamalay, J. C., S45

Kamoun, S., 1315, S45

Kang, S., S46

Kang, S.-H., 58

Karasev, A. V., 1040, S46

Kaser, K. E., S29, S108

Kassemeyer, H.-H., S79

Katan, J., S75

Katan, T., 30, S29, S77

Kaufusi, P., S46

Kayamura, T., 804

Keaster, A. J., S22

Keen, N. T., S44, S82, S83

Keinath, A. P., S56, S83, S125

Keith, L. M., S46

Kekarainen, T., 311

Kelemu, S., S46

Kelly, S., S72

Kelman, A., 28, 29

Kemble, J. M., S82

Kemerait, R. C., Jr., S46, S125

Kempster, V. N., S46

Kent, A. D., S46

Kerrigan, J. L., S47

Khan, M. A., S121

Khan, N. I., S47

Kharbanda, P. D., S101

Khayat, A., S9

Kiewnick, S., S10, S18, S47

Kikkert, M., 63

Kikuchi, A., S69

Kim, D. G., 465 
Kim, D. H., S2

Kim, H. G., 30

Kim, H. H., S126

Kim, H. M., S88

Kim, J. H., S87

Kim, J. S., S58

Kim, K.-S., S58, S126

Kim, M.-S., S47, S60

Kim, S. H. (Canada), S30, S38, S47, S94

Kim, S. H. (Korea), S87

Kim, S. H. (Pa.), S132

Kim, S. J., S47, S87

Kim, Y. C., S47, S48, S62

Kimbrough, J. W., S36

Kimura, I., S69

Kinard, G. R., S48

Kindhart, J. D., S38

Kingston, G. A., S6

Kinkel, L. L., 45, 873, S7

Kirkpatrick, B. C., S8, S83

Kirkpatrick, M. T., S48, S125

Kirkpatrick, T. L., S42, S92, S93, S125, S127

Kistler, H. C., 30, S71, S77, S88, S123

Kjøller, R., 992

Klein, D., 1324

Klein, J. D., S18

Klein, R. E., S108

Kleinhofs, A., S16

Klepzig, K. D., S127

Klessig, D. F., S101

Kliejunas, J. T., S48

Klittich, C. J. R., S48

Kloepper, J. W., 1158, S2, S65, S73, S76, S100, S103

Klopfenstein, N. B., S47, S60, S118

Klosterman, S. J., S17, S48

Kluepfel, D. A., 1248, S96

Knauf-Beiter, G., S37, S51

Knorr, D. A., S29

Knudson, D. L., S12

Ko, W. H., S100

Kobayashi, D. Y., S76

Koch, D. W., S39, S107

Koev, G., 1013

Koh, Y. J., S68

Köhl, J., 568

Koike, S. T., 1046, S6, S9, S19

Kokalis-Burelle, N., S48, S103

Kolaczkowski, E., S113

Kolb, F. L., 410

Kollipara, K. P., 1306

Kolmer, J. A., 171

Kordyum, E., S77

Kormelink, R., 63, 1276

Kosted, P. J., 456, S4, S49

Kousik, C. S., S49, S76

Kouterick, K. B., S49

Krastanova, S., S49

Krause, C. R., S29

Krause, M. S., S49

Kremser, J. J., S50

Kreuze, J. F., 311

Krijger, M. C., 568

Krokene, P., 39

Kropp, M. J., S96

Kruger, W. M., S50, S103

Krupa, S. V., S62

Krupinsky, J. M., S50

Kubisiak, T., S118

Kucharek, T., S46, S50, S80, S125, S126

Kudrna, D., S16

Kukreja, K., S50

Kull, L. S., S57

Kung, R., S51

Kuramae-Izioka, E. E., S50, S70

Kurle, J. E., S114

Kurtz, A. L., S1

Kuti, J., S25, S66, S70

Kwon, C. Y., S30, S50, S112
Labbé, C., S99

La Bonte, D. R., S17

Laccaria bicolor

— genetic engineering, S38

— symbiosis-regulated gene: cloned from, S47; peroxisomal malate synthase, S87

Lacourt, I., 205

Laemmlen, F. F., S108

Laferriere, L., S51

Laflamme, G., 582

Lai, E. M., S51

Laird, D., S2, S37, S51, S88

Lalancette, N., S51, S135

Laliberté, J.-F., 1200

Lamey, H. A., S51, S112

Lamikanra, O., S5

LaMondia, J. A., S51

Lamppa, R. S., S91, S114, S116

Langenberg, W. G., S119

Langham, M. A. C., S112

Langham, R. J., S51

Lanneau, M., 198

Lapierre, H., 818

Larkin, R. P., S51, S130

Larsen, M. J., S60

Larsen, R. C., S52

Latin, R. X., S27

Lavallée, R., S67

Lawrence, G. W., S61

Lax, A. R., 276, S16

Lazarovits, G., S52

Le, T., S52

Leach, J., S4, S38, S50, S60, S77, S91, S114, S117

Leafhopper, virus vectors, laboratory rearing, S121

Lease, R. J., S64

Leath, S., 144, S93

Lecours, N., 582

Lee, C., S117

Lee, F. N., S19, S55, S126

Lee, H., 692

Lee, H. K., S52

Lee, I.-M., 1359, S52, S116

Lee, K. J., S88

Lee, M. E., S52, S116

Lee, R. F., 1040, S14

Lee, S. H., S42

Lee, S.-W., S52

Lee, Y.-H., 58

Lee, Y.-W., 58

Lefèvre, F., 156

Legard, D. E., S123

Lehman, L. J., S62

Leininger, B. L., S61

Leininger, T. D., S53, S60, S100

Leisner, S. M., S2, S53

Lemay, A. V., S53

Lens culinaris, anthracnose, resistance in fungicides, S110

Leonard, K. J., 45, 873, S24

Leong, S. A., S15

Lepoivre, P., 335

Lepping, H.-B., 1020

Leptosphaeria maculans

—biocontrol agent, specific primers, S101

-on Brassica napus, avirulence locus mapping, 1068

—on canola, biotypes, S71

- species complex: identification with conidia as substrate, 1210; PCR for identification, 1210

Lerner, J., S135

Leslie, J. F., 30, S103, S112

Lester, D. G., S97

Letter to the editor

-epidemics, crop-weed interaction, 180

- epidemiology and spatio-temporal dynamics, model, 1000

- gene-for-gene coevolution system, stability, 592

-interaction analysis, de Wit models, strain, 873 -model: fungal mycoparasite host dynamics, energy-based approach, 481; pathogen evolution in cultivar mixtures, pathogen fitness, 492; relative fitness, linear, reply, 490; spore splashing, 1131

- spatial correlation, nonrandomness and aggregation, 84

Lettuce

- downy mildew: in California, S108; warning system, S99

- downy and powdery mildew, chemical management problem, S59

-Sclerotinia minor: drip irrigation suppression, 252; slow-dying resistance, S41

-Verticillium wilt, S86

Lettuce mosaic virus, new host in Brazil, S68

Leucostoma spp., genetic heterogeneity, on peach, 376

Leung, H., 223, S16, S50, S81, S91

Leverentz, B., S96

Lévesque, C. A., 213, S21

Levy, L., S131

Levy, M., 1269

Lewandowski, D. J., S40

Lewis, E. A., S42

Lewis, J. A., S51, S57, S131

Lewis, S. A., S87

Li, C., S75

Li, H. P., S40

Li, J., S16

Li, L. P., S53

Li, R., S53

Li, R. H., 402

Li, S., S53

Li, X.-Z., 1094

Li, Y., S53

Li, Y. J., S53

Liang, X., S53

Lichter, A., S54

Liddell, C. M., S10, S59

Likins, T. M., S131

Lim, T. M., S53

Lin, S. S., S54

Lindbeck, A. G. C., S54

Lindgren, P. B., S42, S43

Lindow, S. E., 1149, S44

Line, R. F., S16, S81

Ling, K. S., S49

Linscombe, S. D., S126

Lipps, P. E., 1078, S47, S112

Lisianthus, Fusarium crown and stem rot, fungicides, S121

Listeria monocytogenes, on apple, growth on fresh apple, S18

Litwiller, D., S117

Liu, H.-Y., 402, S54

Liu, J. Q., 171

Liu, L., 252

Liu, S. J., S67

Liu, Y.-C., 811, S54, S129

Liu, Z., S54, S55, S115

Livieratos, J., 1276

Lo, C.-T., 129

Lo, S. C., S55

Locke, J. C., S10, S29, S128, S131

Lockhart, B. E., S20, S31

Locoism, in cattle, fungal endophyte?, S10

Locust, tree defense factors, characterization, S75

Lommel, S., S19, S56, S89

Long, D. H., S55, S126

Longnecker, M. T., S33

Loper, J. E., 506, S37, S73, S85

López, C., 685

Loria, R., S12, S52

Lotrakul, P., S21, S55

Lotus corniculatus, Rhizoctonia spp., population structure, S26

Louie, R., S15, S55, S75

Louws, F. J., 862, S13, S55, S56, S124 
Lowry, D. S., 402

Lu, S., S79

Lübberstedt, T., 1324

Lübeck, P. S., 698

Lukaesko, L. A., S52, S116

Lumsden, R. D., S37, S57, S131

Lund, R. E., S78

Lundeen, P., S101

Lundquist, J. E., S56

Luo, Y., S56

Luster, D. G., S129, S130, S133

Luvisi, D. A., S91

Lycopersicon sp. (see also Tomato), $\alpha$-tomatine synthesized by, fungal sensitivity, 137

- L. hirsutum, tomato yellow leaf curl virus, resistance, 910

Lynch, R. E., S53

Lyons, E. J., S43

Lyons, N. F., S91

\section{Ma, C., S56}

Ma, H., S56

MacDonald, W. L., S128, S129

MacGuidwin, A. E., S77

Mackenzie, S., S72

Mackie, S. J. W., S56

Macko, V., S17

Macksel, M., S135

Macquaire, G., 198

Macrophomina phaseolina

- host specialization, genetics, S86

-on soybean, planting date and tillage effects, S99

Madden, L. V., 536, 950, 1131, S26, S68, S90, S112

Maffia, L. A., 1116, S20

Magan, N., 960

Magarey, R. D., S57

Magnaporthe grisea

-appressorium formation, sequence analysis and gene characterization, S17

- protein kinase gene, regulatory subunit gene, S32

-on rice: appressorium formation, polyamine relation, 58; in Arkansas, S125; gene profile in chromosome 7, S104; multiple virulence, mechanism, S46; population analysis, rapid, 223; resistance gene, clone, S15

Mahaffee, W. F., S35, S57

Mahmood, T., S57

Maize (see Corn)

Maize chlorotic mottle virus, sgRNA synthesis, long distance cis effect, S78

Maize dwarf mosaic virus, in kernels, vascular puncture inoculation, S75

Maize rough dwarf fijivirus, transmission by puncture inoculation, S55

Maize streak virus

-on corn, symptom quantification by image analysis, 422

-resistance, S15

Majerczak, D. R., S18

Malinoski, M. K., S57

Malpica, J. M., 520

Maluf, W. R., S28

Malvick, D. K., 52, 272, 915

Manandhar, H. K., 735

Manandhar, J. B., S57

Mango

-anthracnose, cultivar response, S120

- anthracnose and stem-end rot, neem extract effect, in Northern Mariana Islands, S9

-bacterial apical necrosis, in Spain, 614

-malformation epidemiology, in Mexico, S67

Man in't Veld, M. A., 922

Manji, B. T., S84

Manulis, S., S6

Manuscript preparation, author's guide, 7

Mao, W., S57

Maramorosch, K., S121
Marasmius spp., on heliconia and red ginger, new disease, $\mathrm{S} 90$

Marathe, R., S3

Marcell, L. M., S116

Marek, S. M., S58

Margosan, D. A., S58, S83

Margot, P., S37, S51, S88

Marmey, P., S58

Maroon, C. J. M., S58

Martin, C. A., S86

Martin, D. P., 422

Martin, E. M., S58, S126

Martin, F. N., S58

Martinez, N., S103

Martínez, O., 292

Martinez-Espinoza, A. D., S58

Martins, O. M., S59

Martinson, C. A., S21, S96, S110, S112, S113, S115, S116, S117, S118

Martyn, R. D., 30, S121

Maruyama, W., S69

Mascagni, H. J., S90

Mask, P. L., S91

Mastari, J., 828

Matheron, M. E., S59

Mathews, D. M., 514

Mathur, S. B., 735

Matsuda, I., S88

Maurhofer, M., 678

Mavrodi, D. V., S59, S80

Mavrodi, O. V., S59

Maxwell, B. D., S13

Mayo, M. A., 1302

Mayton, H., S59

Mazzola, M., 930

McAlpin, C. E., S92

McBeath, J. H., S59

McCabe, P. M., S59

McCann, M., S132

McCarthy, M. K., S4

McCarthy, P. L., S59

McCasland, C. S., S53

McClean, P. E., S86

McClure, S., S22

McCoy, R. J., S60, S62

McCullough, J. A., S6, S136

McDaniel, R., S1

McDonald, B. A., 1087, 1330

McDonald, G. I., S47, S60

McDonald, R. E., S84

McElreath, S. D., S60

McFadden-Smith, W., S60, S95

McGawley, E. C., S9

McGee, J. D., S60

McGiffen, M., S42

McGourty, G., 1149

McGovern, R. J., S60, S121

McGrath, M. T., S60, S136

McIntyre, G. A., S107

McKay, K. R., S51

McLaughlin, M. R., S61

McLean, K. S., S61

McManus, P. S., S7, S45, S61

McMillan, R. T., Jr., S61, S122

McMinn, J. W., S45

McMullen, M. P., S116

McNabb, H. S., Jr., S117, S118

McNair, H. M., S128

McSorley, R., S60

McSpadden Gardener, B. B., S61

Medeiros, R. B., S61

Medina-Mora, C. M., 862

Meeley, R. B., S65

Meinhardt, S. W., S25, S30, S50, S62

Melampsora spp.

-M. larici-populina, on hybrid poplar, gene cluster and resistance, 156

-M. medusae: on poplar, resistance gene, 114; on Populus deltoides, molecular markers, S118
Melcher, U., 428, 1351, S75, S80, S95

Melching, J. B., S136

Melchinger, A. E., 1324

Melgar, J. C., S113

Melin, J. B., S92

Meloidogyne spp.: management, dichloropropene role, S76; on Solanum spp., virulence variation, 658

- M. arenaria, plant tissue and DiTera comparison, $\mathrm{S} 92$

- M. hapla, suppressive by sudangrass as green manure, S97

-M. incognita: on bell pepper, resistance at high temperatures, S89; on cotton, histology, S93; on cotton, relation to Thielaviopsis basicola, S127; egg viability, grass root effect, $\mathrm{S} 48$; rearing by hydroponic method, S79; secretion gene profile, $\mathrm{S} 22$

- M. javanica, nematode-trapping fungi for control, 344

Melon (see also Muskmelon and Watermelon)

—disease management, benzothiadiazole, resistance, $\mathrm{S} 83$

-Fusarium wilt: resistance gene Fom 2, linkage, S104; resistance gene identification, S95

_ gummy stem blight, S122

-Monosporascus root rot: in California, S121; worldwide, S121

Melouk, H. A., S1

Melton, T. A., S35, S44

Mendes-Pereira, E., 1210

Meng, X. Q., S62

Menge, J. A., S22, S52, S85

Menzies, J. G., 396

Mercier, J., S62

Merits, A., 311

Meronuck, R., S26

Messenger, B. J., S62

Meurs, C., 63

Mew, T. W., 300, S91

Meyer, L., 366

Meyer, S. L. F., S131

Meyer, W., S94

Michailides, T. J., 637, S15, S23, S27, S39

Michel, V. V., 300

Michelmore, R. W., S108

Michels, G. J., S12

Michler, C. H., S102

Mickler, C. J., S62

Microarthropod, soil disturbance indicator, S66

Microsphaeropsis sp., Venturia inaequalis interaction, cytochemistry, 605

Midland, S. L., S84

Miedaner, T., 879

Migheli, Q., 30, 673

Mihail, J. D., S99

Mika, J. S., S13

Milgroom, M. G., 811, S54, S129

Miller, C. D., S47, S48, S62

Miller, J. D., S44, S118

Miller, J. S., 190

Miller, L. A., S136

Miller, M. E., S12, S62, S70, S103, S120, S121, S122

Miller, M. L., S108

Miller, P., S28

Miller, S. A., S3, S18, S63

Miller, S. S., S132

Miller, T., S33

Miller, T. C., S63, S108

Miller, W. A., 1013, S63

Milligan, B. G., S9

Mills, D., S54, S63

Mims, C. W., S63, S135

Mink, G. I., S36

Minsavage, G. V., S63

Mirabilis spp.

-M. expansa, ribosome inactivating proteins, biological activity, S133 
-M. jalapa, Clavibacter michiganensis, hypersensitive response, 306

Mirocha, C. J., S113

Misaghi, I. J., S37

Misra, M. K., S32

Mitchell, D. J., 389, S63

Mitchell, S. E., S32

Mitchell, T. K., S64, S126

Mitchell Fetch, J. W., S116

Mitra, A., 730, S56, S119

Miyagawa, H., S66

Mizubuti, E. S. G., 837, S59

Mlikota, F., S64

Mmbaga, M. T., S64

Model

- density- and frequency-dependent fitness, determinants, 45

- de Wit, competitive interaction analysis, letter to editor, 873

- fungal mycoparasite host dynamics, energybased approach, letter to editor, 481

-pathogen evolution, cultivar mixtures, pathogen fitness, letter to editor, 492

- pest management, vegetables, weather network and GIS mapping, S89

-relative fitness estimation, reply, letter to editor, 490

—-spore splashing: environment, 1131; letter to editor, 1131

— surface wetness, weather and forecasts, S57

— viral translation by RNA sequence, S63

Mohan, B. R., 1013

Mohan, S. K., S64

Momol, E. S., S64

Mondal, S. N., 148

Mondjana, A. M., S64

Monilinia spp.

-M. fructicola: on peach, latent fruit infection, S60; on peach and nectarine fruit, development stage, S130; on stone fruit, sporulation and weather, S39

- M. oxycocci: on cranberry, flower infection, S7; on cranberry, fungicide resistant, S61; on cranberry, fungus inhibition in marsh, S45

-M. vaccinii-corymbosi: apothecium emergency, prediction, S79; on blueberry, detection methods, S125

Monosporascus cannonballus

—on melon, tylose formation, S2

- on muskmelon, cucurbitacin content, S70

-Trichoderma as biocontrol agent, $\mathrm{S} 12$

Montez, G., S72

Moore, L. W., S108

Moore, N. Y., 30, 1283

Moorman, G. W., S64

Mor, H., S6

Mora-Aguilera, G., S67, S68, S78

Moraes, F. H. R., S64

Mora-Rodríguez, M. P., 828, 983

Moratorio, M. S., S91

Morehart, A. L., S132

Morelock, T. E., S19

Moreno, P., 685

Morgan, D. P., 637, S27

Morris, B. D., S92

Morris, J. B., S125

Mountain ash, vessel occlusions, pectin secretion, 494

Moyne, A. L., S65

Muehlbauer, G., S73

Mueller, D. S., S65

Mujeeb-Kazi, A., 890, S82

Mukerji, A., S65

Müller-Schärer, H., 180, S99

Mullin, P., S65

Multani, D. S., S65

Mundodi, S. R., S65

Mundt, C. C., 708, 1330, S19

Munkvold, G. P., 550, S32, S82, S116
Muñoz, F., 306

Murphy, C., 576

Murphy, J. F., S65, S82, S91

Murphy, J. P., 144

Murray, A. K., S35

Murray, T. D., S106, S107

Mushroom, shiitake, hardwood sawdust medium, S69

Muskmelon (see also Melon)

-Alternaria leaf blight, chlorothalonil application, factors, S25

- CMV protein, temperature effect, S5

-Fusarium wilt: botanical extract effect, S10; variation in Japanese strains, 804

-root rot, polygalacturonase relation, S103

- vine decline, in Central America, S120

Musselman, C. A., S49

Musselman, L. J., 563

Mycosphaerella graminicola, on wheat

—immigration and reproduction in field, 1330

- virulence variation, S19

Mycotoxin

-aflatoxins, compounds inhibitory to, S89

-deoxynivalenol and nivalenol, Fusarium $\mathrm{cul}$ morum in rye, 879

Myers, J. R., S86

Myers, L., S42

Myers, O., S56

Nabizadeh-Ardekani, F., S59

Nagahama, K., 1205

Nagahashi, G., S66

Nair, H., S17

Naito, S., S66

Nakaho, K., S66

Nakajima, T., S66

Namiki, F., 804

Narvaez, D. F., S66

Nass, P. H., 1031

Navas-Castillo, J., 685

Navas-Cortés, J. A., 828, 1338

Nawar, H., S25, S66

Ndowora, T. C. R., S20

Nedukha, O., S77

Neher, D. A., S66

Neill, G. B., S93

Nel, L. H., 366

Nelson, B. D., 1056

Nelson, E. B., 129

Nelson, M. E., S108

Nelson, M. R., S43

Nelson, R. J., 223, S50, S91

Nelson, R. S., S22, S40

Nematicides, plant derivatives, S92

Nematodes

-management agents, problems and potential, S131

-trapping fungi, 344

Nemchinov, L., S66

Nemchinova, Y. P., S67

Nesmith, W. C., S37, S130

Nester, S., S9, S132

New, L. L., S27

Newcombe, G., 114

Newman, M. A., S85

Newton, M. R., 45, 873

Ng, C. K. J., S67

Niblack, T. L., S99

Niblett, C. L., S14

Nicholson, R. L., S55, S96

Nickel, C. D., S3

Nicole, M., 494, 1141

Nicole, M. C., S67

Nicotiana spp. (see also Tobacco)

$-N$. benthamiana, tobamovirus or dianthovirus movement proteins, 666

-N. tabacum: Peronospora tabacina tissue culture, host-pathogen interaction, S130; salicylic acid, glucosylation, 692

Niggemeyer, J., S67, S69
Nigh, E. L., S135

Nikolaeva, O. V., 1040

Niks, R. E., 856

Nishi, K., 804

Nissenbaum, T., S137

Noble, J. K., S126

Nokes, S. E., S99

Norelli, J. L., S8, S134

Noriega-Cantú, D. H., S67

Norman, D. J., S67, S122

Northover, J., S67, S104

Northover, P. R., S68

Norton, A. P., S30

Nou, I. S., S68

Novacky, A. J., S40

Ntahimpera, N., 536, 950, S68

Nuss, D. L., 598

Nutter, F. W., Jr., 895, S68, S111, S113, S115, S117, S118

Oak

-bacterial wetwood: arborsonic decay detector, S100; properties, S100

-decline, in Mexico, S88

—insects and diseases, softwares for rapid recognition, S97

—wilt, in live oak, aromascan analysis, S97

Oat

-barley yellow dwarf virus: localization of 17-kDa protein and RNA, 1031; tolerance, loci, 410; transgenic tolerance, 1013

- crown rust, partial resistance, S82

- foliar fungicides, disease and yield, S111

- mitochondria, permeability transition, S20

- $\mathrm{Vb}$ locus, molecular markers, S18

Obituaries

—Lindsay M. Black, 872

-Frank Leslie Howard, 28

-George Blanchard Lucas, 29

-William J. Zaumeyer, 480

O'Brien, J. G., S37, S88

Ochoa-Martinez, D. L., S68

O’Donnell, K., 30

Odontoglossum ringspot virus, infectivity influenced by amino acid, S102

Odvody, G., S123

Oelke, L. M., S117

O'Garro, L., S120

Ohm, H. W., 851

Ohr, H. D., S42

Oidium sp., on poinsettia

- colony development and infection, 105

- conidial germination, cover photo, February

-leaf infection, temperature and humidity effect, S134

Okuley, J. J., S45

Olalla, L., 614

Oliveira, F. A., S68

Olmos, A., 198

Olszewski, N. E., S20

Omer, M. A., S69

Omura, T., S69

Ona, I., S91

Ong, C. A., S41, S69

Onion (see also Allium porrum)

- soft rot, Pseudomonas marginalis cause, S64

Opgenorth, D., 862

Ophiosphaerella spp., on bermudagrass, genetic diversity, S96

Ophiostoma spp., detection by PCR, S47

-O. piceae: extracellular lipase, encoding gene, S38; on spruce, bark beetle association, 39; sapstaining fungus, genetic variability, S30; scytalone dehydratase gene, cloning, S94

-O. ulmi: on elm, O. novo-ulmi comparison, S24; on Prunus pensylvanica, tree sections, cover photo, June; spore deficient mutants, S113; vessel occlusions in trees, pectin secretion, 494

Oplinger, E. S., S52, S114, S116 
Opuntia spp., viruses, S16

Orchid

- Rhizoctonia solani, mycorrhizal agent, S13

- virus detection in, electrophoresis, S27

Ordoñez, M. E., 265

Orf, J. H., S16

Ornamentals, Research Program IR-4, S29

Orozco, F., S88

Ortega, S., S109

Orum, T. V., S43

Osada-Kawasoe, S., S77

Osborn, T. C., 1068

Osborne, L., S69

Osborne, W. W., S126

Osorio, F., S69

Ospina-Giraldo, M. D., S16, S69

Østergård, H., 492

Ostrofsky, A., S43

Ostrow, K. M., S11

Ostry, M. E., S35, S37, S95

Otero-Colinas, G., S67

Otrosina, W. J., S5, S48

Ou, L.-T., S76

Ouellette, G. B., 494

Overstreet, C., S9

Owens, R. A., S103

Oyarzun, P. J., 265

Ozdemir, Z., S136

Ozone, spore mortality and fungi, on humid conditions, S58

Pacumbaba, R. O., Jr., S69

Pacumbaba, R. P., S69

Padidam, M., 1262

Padovan, A. C., S68

Page-Lester, S. A., S69

Pai, S., S70

Pair, S. D., 428

Paiva, N. L., S65

Palta, J. P., S64

Pan, S. Q., S53

Panabières, F., 205

Panaccione, D. G., S131, S133

Pangga, I. B., S70

Panicum mosaic virus

—capsid, on pearl millet, S74

-replication, protein, S6

Panigrahi, S., S29

Pantoea spp.

- P. agglomerans, on radish, acquired resistance, S36

- $P$. citrea, in pineapple, glucose dehydrogenase gene, S73

- P. stewartii, on corn hrp gene regulation, $\mathrm{S} 18$

Pantuso, F., S30, S32

Papaver spp., Myrothecium verrucaria for control, adjuvant carrier, S101

Papaya, phytoplasma, yellow crinkle disease epidemiology, S68

Papaya ringspot virus

-on Carica papaya, technology transfer between Cornell and EMBRAPA, S137

-resistance factors, S84

- transgenic cultivars resistant to, S31

Pappu, H. R., S7, S71, S125, S127

Pappu, S. S., S71

Parfitt, D. E., S15

Park, D.-S., 556

Park, J. W., S21, S70

Parke, J. L., S37, S46

Partridge, J. E., S46

Pasini, R., S36

Pasteuria penetrans

- biochemical events, S11

-nematode attachment, observations, S26

Pataky, J. K., S24, S70

Paterson, A. H., S99

Paul, L. E., S2

Paul, R., S1
Paulin, L., 311

Paulitz, T. C., S135

Payan, L., S18

Payne, G. A., S98

Payton, M., S42

Pea

-Aphanomyces euteiches: diversity in central and western USA, 915; on roots of, oospores and enzymatic activity, 992

-Aphanomyces root rot, strain variation, 52, 272

-diseases suppressed by Pseudomonas corrugata, S17

-Fusarium solani, DNA-damaging agents, S17

—inducible protein, epitope, S48

Pea enation mosaic virus

- detection in aphids, S52

- mutational analysis of $\mathrm{VPg}, \mathrm{S} 82$

Peach

-brown rot, fungicide, interactions, S26

-fruit rot, benomyl and propiconazole for, S28

-Fusicoccum canker: inoculum availability, S51; yield loss in New Jersey, S135

- icosahedral virus in Korea, S126

-Leucostoma spp., genetic heterogeneity, 376

- postharvest diseases, biocontrol microorganisms, S104

—rust, early and late epidemics, in California, S84

—scab, fungicide, S18

Peanut

-Bowman-Birk trypsin inhibitor gene, characterization, S73

-leaf spot: systemic resistance induced, S103; weather based advisory, S5

- potyvirus, seedborne in Brazil, characterization, S71

- Sclerotinia blight, fungicides and resistant genotypes, S53

— soilborne fungi in Florida, S46, S125

- tomato spotted wilt virus on, spatial patterns, S127

Peanut stunt virus

- satellite RNA, mapping sequence determinants, S31

- strain BV-15, natural reassortant, 92

-on tobacco: cytoplasmic inclusions, 1192; protoplasts, inclusion structures, cover photo, November

Pear

- fire blight, antagonist factors, 506

- fruit russet, bacteria and indole-acetic acid, 1149

-fruit russet and bacteria, 1149

Pecan, scab

— fungicide programs, S79

- fungicides and weather based model, S23

-lesion development factors, 1294

-management alternatives, S27

-resistance and variation, S124

Pedersen, W. L., 1306, S3, S10, S57, S65

Peever, T. L. (Fla.), 724

Peever, T. L. (N.Y.), 811, S54

Pegg, K. G., 1283

Pelargonium line pattern virus, in geranium, detection with probe, $\mathrm{S} 48$

Pelargonium ringspot virus, genome organization, S48

Pelosi, R. R., S73

Penaloza-Vazquez, A., S102

Peng, Y., S35

Penheiter, A., S103

Pennypacker, B. W., S136

Pennypacker, S. P., S49

Pentaclethra macroloba, insect-toxic agglutinin from seeds, characterization, S75

Pepper

- geminivirus, in Costa Rica, S21

- major resistance genes, acquired resistance, S76

Peppermint, Trichovirus effect on field performance, S19

Percich, J. A., 52, 272, 915, S26
Peres, N. A. R., S70

Pérez-García, A., 614

Periconia circinata, peritoxins, biosynthesis, S17

Periwinkle, aster yellows, detection of mRNA, S109

Pernezny, K., 33

Peronospora spp.

- P. sparsa, on rose, detection, $\mathrm{S} 2$

- P. tabacina, on tobacco, long-term culture, S37

Perry, J. M., S79

Perry, K. L., 851, S67

Peterek, S. A., S70

Peters, D., 63, 1276

Petersen, J., S116

Peterson, A. H., S65

Peterson, C. M., S74

Peterson, G. L., S9, S29, S70, S131

Peterson, L. G., S76

Peterson, P. D., Jr., S71

Pettis, G. S., 1179

Pettway, R. E., 1087, S71, S77

Pfleeger, T. G., 708

Phaseolus vulgaris (see also Bean)

- anthracnose, isolates in Mexico, characterization, 292

- chitinase gene and protein induction, by potato leafhopper, S40

-Fusarium solani on, chlamydospore factors, 148

-resistance gene I, cloning, S72

-rust, $U r$-3 resistance gene, S67

-web blight, resistance screening method, S121

-white mold, calcium and thiophanate-methyl effect, S34

Phellinus linteus, molecular analysis, S87

Phelps, R. H., 1262

Phialophora gregata

—adzuku bean and soybean isolates, molecular markers, S115

-on annual and perennial legumes, survival, S111

- genetic variation, AFLP and ISSR analysis, S62

Phillips, D. V., S71

Phillips, J. G., S131

Phomopsis spp., on peach, vegetative compatibility and virulence, $\mathrm{S} 28$

- P. longicolla, on soybean, molecular identification in phylogeny, 1306

Phylloplane, microbial populations, assessment, S4

Phytoalexins, cucumber, silicon-mediated accumulation, 396

Phytophthora spp., on citrus, outbreaks in Florida, 724; in nursery and irrigation water, S92; on ornamental crops, containers, $\mathrm{S} 23$; on pistachio, root and crown rot resistance, $\mathrm{S} 15$; reverse dot blot hybridization, identification, 213

-P. capsici: dimethomorph for zoospores, efficacy, S136; on pepper, biocontrol with Trichoderma, S59; on tomato and pepper, Messenger control in Florida, S78

- P. cinnamomi, catalase enzyme, activity, S120

-P. infestans: Canadian populations, characterization, S20; clonal lineage, development and temperature, 837; clonal lineage, elicitor protein, 1315; fungicide sensitivity, assay comparison, S132; mating type change and fungicides, S90; Nicotiana resistance, potato virus $\mathrm{X}$ vector, S45; oospore survival, factors, S58; population changes, migration and recombination, 939; on potato, epidemics in the Netherlands, factors, 754; on potato, isolate aggressiveness, Washington and Oregon, 190; on potato, leaf assay for resistance evaluation, S33; on potato, oospore role in epidemic, archival and herbarium materials, 1120; on potato, past epidemics and oospore role, 1120; on potato, PCR detection in tubers, S95; on potato and tomato, in Morocco, S132; sporangia in soil, fungicides, S23; on tomato, isolate variation, S129; on tomato and potato, in Ecuador, 265; zoospore germination, temperature and humidity effect, S77 
-P. nicotianae: on citrus, histology of root infection, 389 ; $P$. cactorum hybrid, isozyme analysis, 922

- P. palmivora, on citrus, histology of root infection, 389

- P. parasitica: on citrus, soil surfactant for control, S62; on tobacco, virulence diversity, nuclear RFLPs, 205

$-P$. sojae: race 25 , molecular variation, $\mathrm{S} 115$; race distribution, in soybean, $\mathrm{S} 42$; on soybean, mutant recovery, S26; on soybean, races in Indiana, S115

Phytoplasma

-DNA analysis in Japan and Korea, S88

- ecology and genomic diversity, symposium, 1359

-identity and disease etiology, symposium, 1372

—ribosomal DNA, RFLP analysis, S35

-Western $\mathrm{X}$, identification and characterization, S8

Piccinni, G., S12, S27, S71

Pichia anomala, antagonist to Botrytis cinerea on apple, 335

Pielaat, A., 1131

Pierson, E. A., S71

Pierson, L. S., III, S71

Pieters, R., 922

Pijut, P. M., S102

Pilgeram, A. L., S89

Pilgeram, A. P., S4

Pilowsky, M., 1101

Pine (see also White pine)

-black-stain root disease, site factors, S48

-loblolly, wounding response and chitosan, S127

- loblolly and slash, fusiform rust, tree traits, S93

-Monterey, pitch canker, S85

- pitch canker, resistance, S9

- ponderosa, canopy structure and Armillaria root disease, digital image analysis, S56

Pineapple

-mealybug wilt: associated virus, transmission, 1224; symptoms, growth, and flower production, S80; vectors, 1224

-Rotylenchulus reniformis, management in tropical cover crops, S94

Pinkerton, J. N., 122, 1165, S42, S108

Pinnow, D. L., S125

Pinus spp., blue-stain fungi, pathogenicity, S5

-P. edulis, decline, analysis, $\mathrm{S} 4$

$-P$. palustris, decline, blue-stain fungi, S5

-P. resinosa: shoot blight, uneven-aged stands, S37; Sphaeropsis shoot blight and canker, phenolic concentration, 245

-P. taeda, fusiform rust, rhizobacteria and resistance, S26

Pio-Ribeiro, G., S71

Piper (see Pepper)

Pirone, T. P., S94

Pistachio

-Alternaria leaf blight: inoculum source, S27 resistance, $\mathrm{S} 15$

—fungal decay, kernel staining, S23

Pita, J. S., S71

Pitz, K. Y., S31

Plant extracts, antifungal activity, S25

Plant stress, infrared detection system, development, S12

Plasmopara viticola

—azoxystrobin sensitivity, distribution, S98

-in grape, resistance, chemical and pathogen-induced, S98

Platt, H. W. (Bud), S20

Plattner, R. D., S73

Plectosporium tabacinum, on hydrilla, model system, S83

Ploetz, R. C., 30, S72

Plum pox virus, serotypes, typing method, 198

Plyler, T. R., S72

Podila, G. K., S38, S47, S87
Poinsettia

- powdery mildew: biological and chemical fungicides, S135; heat effect on germination, 105; resistance conferred by peptides, S83

-Rhizoctonia stem rot, biocontrol agents, S42

Poleij, L. M., 658

Polek, M., S72

Polston, J. E., S65, S82, S122

Ponciano, G., S117

Poncirus trifoliata, citrus tristeza virus on, resistance, S31

Pongam, P., 1068

Pontif, M. J., S9

Pope, E. J., S13

Popham, T. W., S72

Poplar

- leaf rust, molecular epidemiology, S9

—vessel occlusions, pectin secretion, 494

Poplawsky, A. R., S17, S72

Populus spp.: rust, resistance factors and gene cluster, 156; rust, resistance gene, 114

- $P$. tremuloides (see also Aspen), beetle, nematode, and fungus association, S47

Porchas, M., S59

Poromarto, S. H., 1056

Porter, B., S101

Porter, P. M., S16

Postharvest pathology

— gray mold, Pichia anomala antagonism, 335

- pesticide use in food crops, market analysis, S130

Postman, J. D., S72

Potato (see also Solanum spp.)

—diploid hybrids, late blight resistance, S55

—dry rot, Enterobacter as antagonist, S118

- early and late blight, climate data comparison and models, S107

- early blight, tuber decay and tuber performance, S29

—early dying, management in irrigated regions, S106

-Fusarium dry rot, biocontrol with bacteria, S47

-late blight: ACROBAT MZ effect, S6; clonal lineage in Phytophthora, temperature effect, 837; cloning of resistance gene analogs, S54; epidemic development and factors, 754; fungicides, S86; isolate aggressiveness in Washington and Oregon, 190; late blight resistance, molecular markers, S55; lipoxygenase relation in tubers, S74; oospores and epidemics, archival and herbarium materials, 1120; predictive model, S36; resistance evaluation of tubers, S74; specificity in Ecuador, 265

-nematode and Verticillium wilt, stem colonization, S77

-Pratylenchus neglectus and Verticillium dahliae, relation, $\mathrm{S} 3$

-Rhizoctonia solani, mycorrhizal effect, S102

- scab, thaxtomin A production, 442

- silver scurf, severity in certified seed, S31

- spindle tuber viroid, nuclear targeting signals, S103

- surface blemish on tuber, Colletotrichum cause, S136

-Verticillium dahliae, pathotype virulence, S69

—viruses, tissue culture, 437

Potato leafroll virus, Buchnera interaction, amino acids, S39

Potato virus A, isolate differences, hypersensitivity, 311

Potato virus $\mathrm{Y}$

- egg-plant mottle virus a strain of, serology, S7

-leaf-drop, hypersensitivity, 1073

-new strain in Brazil, properties, S64

Potti, R. S., S72

Poupet, A., 205

Powell, C. A., S73

Powelson, M. L., S106, S107

Power, R., S132
Powers, K., S85

Pozo, A., 265

Pratt, R. G., S61

Pratylenchus spp.

- P. penetrans, on potato, reduction by marigolds, $\mathrm{S} 128$; in potato, resistance, $\mathrm{S} 11$

-P. thornei, Fusarium oxysporum interaction on chickpea, 828

Praveen, S., S7

Press, C. M., S73

Preston, J. F., S11

Price, L. D., S73

Pritsch, C., S73

Proctor, R. H., S73

Proffitt, T. W., S12

Programmed cell death (apoptosis), heterokaryon incompatibility and nuclear DNA degradation, S58

Provin, E. M., S33

Prunus necrotic ringspot virus, phylogenetic relation, S36

Prunus spp., virus resistance, coat protein mediated cross-protection, $\mathrm{S} 131$

Pruss, G. P., S3

Pryor, A., S41

Pryor, B. M., S73

Pryor, T., S87, S95

Pscheidt, J. W., S35

Pseudocercosporella herpotrichoides

-in Triticum tauschii, resistance mapping, S106

-on wheat, genetic analysis of resistance, S106

Pseudomonas spp., diacetylphloroglucinol distribution, monoculture, $\mathrm{S} 80$; in rhizosphere, diacetylphloroglucinol-producing strains, S59

- $P$. aureofaciens, ovicidal effect on ring nematode, $\mathrm{S} 96$

-P. chlororaphis, insect-mediated dispersal, 1248

-P. fluorescens: competitive fitness in soil, cytochrome c role, S76; survival and rpoS gene, $\mathrm{S} 85$; tobacco necrosis virus resistance induced by, 678; on wheat roots, soil suppression, S74

-P. putida: catalase, induction by $\mathrm{H}_{2} \mathrm{O}_{2}, \mathrm{~S} 62$; on hyphae or citrus root tips, cloning genes, S52; population increase in soil, S85; root colonization, manganese- and iron-superoxide dismutase, $\mathrm{S} 48$; rpoS gene and resistance to oxidative stress, S62

- $P$. solanacearum, ginger race in Hawaiian soils, medium, $\mathrm{S} 122$

-P. syringae: on Arabidopsis, systemic acquired resistance, 450; biosynthesis of syringomycin and syringopeptin, genomic region, S79; carbon source utilization, TLP2 mutants, S44; dnaK gene, cloning, S46; DNA marker for identification, S68; ethylene-forming enzyme from, efe gene, 1205; on leek, description, new pathovar, 844; on mango, in Spain, 614; pathogenicity, exopolysaccharide alginate role, S102; superoxide dismutase genes, transcriptional regulation and mutagenesis, S47; temperature-responsive loci, S91; on tomato, leaf factors and toxins, 1094; on tomato, secretion apparatus, analysis, S40; UV-tolerance locus, sequence diversity, S87

Puccinia spp.

$-P$. coronata, biocontrol agent for wild oat, S13 $-P$. graminis, on wheat, resistance genetics, 171

-P. hordei: on barley, prehaustorial resistance, inappropriate rust fungi, 856; on barley, resistance genes Rph 9 and Rph12, 76; on barley, worldwide virulence, $\mathrm{S} 28$

-P. pelargonii-zonalis, urediniospores, longevity, $\mathrm{S} 44$

-P. recondita: on wheat, slow-rusting gene $L r 46$, 890 ; on wheat, in wheat and wild oat communities, effect, 708

-P. sorghi: on corn, resistance and loci mapping, 1324; PIC13 resistance gene, S95

-P. striiformis: on barley, field resistance, S77; on barley, quantitative resistance and multivar- 
iable comparison, S78; on barley, resistance genes, diallel analysis, S16; on wheat, marker genes, resistance gene analog polymorphism, S81

- P. substriata, on pearl millet, hybrids, resistance and yield stability, S97

Pujic, P., S16

Pujol, C. J., S73

Punja, Z. K., 939

Purcell, A. H., S83

Purcifull, D. E., S122

Pyrenophora tritici-repentis

-chlorosis-inducing toxin, wheat gene, S25

-spore production, in wheat straw, S50

-on wheat: PTR ToxA binding, plasma, S62; races and RFLP mapping, S24

-on wheat and grasses, races in US Great Plains, S114

Pyricularia spp.

-P. grisea: population structure, vegetative compatibility use, S19; on rice, new Chinese resistance gene, 822; on rice, transmission from seed to seedlings, in Arkansas, S126; on tall fescue, temperature and leaf wetness effect, S90

-P. oryzae, on rice, blast suppression from, 735

Pythium spp.: diverse dot blot hybridization, identification, 213; infection, asymptomatic, cytochemistry, 234; on pepper and tomato, growth effects, S63; on rice, infection sites and factors, 1255

- P. aphanidermatum: soil suppressive to, soil factors, S34; on tobacco, recovery in transplanting, S35

-P. arrhenomanes, on sugarcane, growth and root rot affected by herbicide, 530

- P. paddicum, on turfgrass, first record in Canada, S21

-P. torulosum, Bacillus biocontrol agent, genetic basis, $\mathrm{S} 83$

-P. ultimum: on cucumber, biocontrol with Trichoderma, 673; potato, seed piece decay, tuber wound healing effect, S117

Qi, M., S101

Qiu, D., S65, S74, S96

Qiu, J., S74

Qiu, W. P., S70, S74

Quercus phellos, decline, factors in wildlife refuge in Louisiana, S53

Quimby, P. C., S104

Quiot, J. B., 198

Raaijmakers, J. M. S59, S74, S80

Rabenstein, F., 311

Rachdawong, S., S74

Rademacher, M. R., S74

Radopholus similis, on banana, phenol effect in roots, 1141

Ragland, M., S31

Ragozzino, A., 1200

Raikes, C., 446

Rainfall, kinetic energy, electronic sensor, 950

Rajaei, H., 472, 740

Rajamäki, M., 311

Rajamannar, M., S7

Rajmohan, R., S82

Ralstonia solanacearum

-Arabidopsis thaliana: cover photo, April; resistance, 330

- detection in tomato rhizosphere, PCR, S59

- polygalacturonase role in colonization of tomato, S41

-race 3, lipopolysaccharide of, recombinant antibodies, 795

—in tobacco, resistance from human lactoferrin, 730

-on tomato: soil amendment effect on survival, 300; in xylem, S66

Ramanjulu, V., S74

Ramón-Vidal, D., 673
Ramundo, B. A., S66

Randhawa, P., S84

Randles, A., S59

Randles, J. W., 774

Rangaswamy, V., S104

Rao, A. L. N., 666

Rascoe, J., S75

Raskin, I., 692

Rasmussen, J. B., S30, S50, S112

Rasmussen, S. L., S2

Rasmusson, D. C., S27

Rathburn, H., S75

Raupach, G. S., 1158

Ravelonandro, M., S131

Raymer, P. L., S71

Rebolledo, O., S88

Red clover necrotic mosaic virus

—assembly sequence, vector-based system, S56

-RNA replication, terminal stem-loop structure, S96

Reddy, D. V. R., 872, S71

Redinbaugh, M. G., S75

Reed, B. M., S72

Reedy, R., S76

Reese, C. D., S16

Reeser, P., S42

Reeves, D., S111

Reidy, B., 252

Reilley, A. A., S12

Reimann-Philipp, U., S75

Reimmann, C., 678

Rekah, Y., S75

Resendiz, R., S67

Resistance

-Arabidopsis thaliana to bacterial wilt, 330

- barley to leaf rust, genes $R p h 9$ and $R p h 12,76$

- barley to rust, inappropriate rusts, 856

—citrus to Phytophthora spp., histology, 389

- corn to gray leaf spot, 972

— fatty acid modification in plants, S94

- poplar to rust: gene cluster, 156; major gene, 114

- potato to viruses, tissue culture methods, 437

- rice to blast, Chinese resistance gene, 822

- tomato to tomato yellow leaf curl virus, 910

- wheat, rice, and barley, high genetic similarity, S33

- wheat to leaf rust, gene $\operatorname{Lr} 46,890$

-wheat to powdery mildew, major gene, 144

- wheat to stem rust, cultivar genetics, 171

Revers, F., 198

Reviewers, acknowledgment of, 4

Rey, M. E. C., S125

Rey, P., 234

Reynard, D. A., S93

Rezende, J. A. M., S75

Rhizobacteria

- growth-promoting: biocontrol of cucumber pathogens, 1158; root colonization and plant response, S76

Rhizoctonia spp.: on bean, induced systemic resistance, 359; on radish, management, S18

- R. solani: anastomosis groups, killing reaction detection, S35; on bean and peanut, nucleotide sequence analysis in Brazil, S50; biocontrol with Bacillus, in bedding plants, S67; on creeping bentgrass, assessment by radiometry, 446; herbicide effect on mycelium and sclerotia, S36; in potato, AG3 and AG4 groups, S14; in potting mixtures, suppressed by compost, 764; on rice, recombination and gene flow, S71; root rot from, mycorrhizal fungi and transplant survival, S135; on snapbean, potash fertilizer effect, S124; on soybean, biocontrol with binucleate Rhizoctonia, 1056; on sugar beet, oligosaccharides and defense response, S35; on tall fescue, resistance components, S33; on wheat, crater disease strain, 366

Rhizosphere

—bacterial communities, FT-ARDRA, S61

—containerized plants, metalaxyl fate, S70
Rhodes, L. H., S99

Rhododendron spp., tissue proliferation in Virginia, $\mathrm{S} 131$

Rhodosporidium toruloides, leaf surface adhesion, factors, $\mathrm{S} 12$

Rhynchosporium secalis, on barley, histopathology, S52

Ribes nigrum, reversion disease, phage display, 230

Ricci, P., 205

Riccioni, L., 1306

Rice

-bacterial blight: molecular changes in gene, S91; peroxidase and xylem parenchyma, S38; resistance and quantitative trait loci, S50

-blast: appressorium formation inhibited by polyamines, 58; Chinese isolate, new resistance gene, 822; plant age effect, S55; population analysis of pathogen, 223; suppression by avirulent species and Bipolaris sorokiniana, 735

-leaf and neck blast: silicon and host resistance, S80; silicon fertilization and fungicides in Colombia, S126

-on Pythium spp., infection sites and factors, 1255

— sheath blight, major gene resistance, S126

— stem rot, yield reduction, inoculum level, relations, S17

-Xanthomonas oryzae, defense response compounds, S60

Rice dwarf virus, virus adsorption to insect vector cells, S69

Rice tungro bacilliform virus

- coat protein characterization, mass spectrometry, S58

- polymerase gene and transmission, S69

Rice tungro spherical virus, on transgenic rice, resistance, $\mathrm{S} 41$

Rice, J. D., S11

Rich, P. E., S76

Richards, W. C., S113

Richardson, E. A., S63

Richardson, M., S94

Richter, T., S95

Ridout, M. S., 1000

Riedel, R. M., S99

Riegel, C., S76

Riegel, D. M., S97

Riggs, R. D., 465, S28, S89, S95

Riley, K., S72

Riley, M. B., S70

Rimelspach, J. W., S30

Riopel, J. L., 70

Rioux, D., 494

Ristaino, J. B., 1120, S12, S90, S95

Ritchie, D. F., S49, S76

Rivas, G., S13

Rivas-Davila, J. E., S76

Rivas-Davila, M. E., S76

Rivera-C., J. M., S118

Rivera-Smith, C., S19

Rivera-Vargas, L. I., S120, S122

Rizzo, D. M., S76, S108

Roark, R. S., S9

Robbins, J. T., S121

Robbins, R. T., S77

Roberts, B. W., S24

Roberts, D. P., S76

Rodríguez, R., 292

Rodríguez-A., J., S67

Rogers, J. D., S47

Rokka, V-M., 1073

Rollins, J. A., S76

Rolshausen, P. E., S76

Romaine, C. P., S16, S69, S86

Romero, A. M., S76

Ronald, P., S15

Roncadori, R. W., S5

Room, P. M., S70, S98

Roossinck, M. J., S5, S52 
Rose

-blackspot, winter treatment, S9

- gray mold: calcium sulfate effect, 1116; postharvest treatments, S20

- powdery mildew, biological and chemical fungicides, $\mathrm{S} 135$

Rosellinia bunodes, on coffee, Pseudomonas effect, S13

Rosendahl, S., 992

Rosewich, U. L., 1087, S71, S77

Ross, D. C., S6

Rosskopf, E. N., S63

Rotenberg, D., S77

Rothrock, C. S., S48, S92, S93, S125, S127

Rott, P., S20

Rotylenchulus reniformis, in cotton, in Tennessee, S85

Rouse, D. I., S64, S77

Routh, G., 1238

Rouxel, T., 1210

Rowe, R. C., S69

Rowhani, A., 1231, 1238, S32

Roy, S., 576

Royse, D. J., S16, S69

Rubsam, R. R., S68, S113

Rudolph, K., S59

Ruiz-Herrera, J., S58

Rundell, P. A., S73

Rupe, J. C., S42, S48, S55, S77, S125, S127

Rush, C. M., S12, S27, S37, S57, S71

Rush, M. C., S126

Russell, B. W., S63

Russin, J. S., 276, S16, S32, S86, S90

Russo, J. M., S57

Russo, P., 437

Rutherford, M. A., 30

Ryba-White, M., S77

Rybicki, E. P., 422

Ryder, E. J., S41, S86

Rye

- ergot: extracellular catalase secretion, role in dis ease, 744; xylanolytic system, gene characterization, 1020

-Fusarium culmorum, deoxynivalenol and nivalenol, 879

Ryegrass mosaic virus, in New Zealand, S95

Rymovirus, wheat streak mosaic and brome streak mosaic viruses not members of, 782

Saavedra, E. D., S122

Sabo, A., S28

Saguaro cactus virus, alanine mutagenesis, infectivity, S51

Sahin, F., S63

Salas, B., S77, S117

Saldarelli, P., 1238

Salix spp., beetle, nematode, and fungus association, S47

Sams, C. E., S18

Samson, R., 844

Sanchez, V., S13

Sanders, C., S102

Sandler, H. A., S77

Sandoval-Islas, J. S., S77, S78

Sandrock, R. W., 137, 939

Sands, D. C., S4, S10, S13, S89

Sanford, J. C., S83

San Francisco, M. J. D., S91

Sangare, A., S71

Sanger, M., 1192, S31

Sanogo, S., S78, S113

Santos, R. C., S64

Sapers, G. M., S43

Sarah, J. L., 1141

Sarath, G., S103

Sasinowski, M., S104

Sato, M., 1205

Saunders, S., S83

Savelle, A. T., S79
Sawyer, T., S78

Scardaci, S. C., S17, S106

Schaad, N. W., S7, S9, S29, S84, S101, S131

Schading, R. L., S78, S96

Schafer, J., S19

Schardl, C. L., S8, S19, S37, S130, S131, S133

Scharen, A. L., S78

Schaus, P. J., S16

Scheck, H. J., S78

Scheets, K., S78

Schergaut, M., S91

Scherm, H., S18, S26, S79, S125

Schiller, C. T., S3, S79, S136

Schisler, D. A., S47, S118, S129

Schlenz, M. L., S79

Schmidli-Sacherer, P., 678

Schmidt, R. A., S33

Schmitthenner, A. F., S22

Schneider, A. T., S107

Schneider, K., S104

Schneider, R. W., 1255, S79

Schneider, S., S79

Schoelz, J., S2

Schollenberger, M., 879

Scholthof, H. B., S21, S70, S75

Scholthof, K.-B. G., S6, S74

Scholz-Schroeder, B. K., S79

Schots, A., 795

Schraeder, P. L., S12

Schroeder, K. L., S59, S80

Schubert, K. R., S39, S40, S75

Schuhmacher, U., 879

Schulbach, K. F., 1046

Schultz, M. H., S82

Schultz, P. M., 895

Schulze, D. G., S113

Schulz-Wulkow, S., S35

Schumacher, E., S75

Schuster, D. J., S65

Schuster, S., S27

Schwarczinger, L., S131

Schwartz, H. F., S36, S107

Sclerostagonospora salsolae, on Salsola kali, biocontrol, S131

Sclerotinia spp.

-S. homoeocarpa, hypovirulent isolates, dollar spot suppression, 788

$-S$. minor: on lettuce, drip irrigation suppression, 252; on peanut, resistance, $\mathrm{S} 1$

-S. sclerotiorum: airborne ascospores, microthread technique, S116; alfalfa after soybean, establishment, S136; apothecium production, $\mathrm{S} 41$; apothecium production, light, temperature, and moisture effect, S87; apothecium production, prediction, S118; ascospore survival, $\mathrm{S} 91$; on bean, airborne populations, S114; biocontrol agent for spotted knapweed, S4; Coniothyrium minitans as control, in beans, S11; mycoflora parasitic to sclerotia, S115; sclerotial development, oxalic acid production, S76; sclerotial germination, moisture and temperature effect, S36; species distinction, RAPD data, S85

Sclerotium oryzae, on rice, residue treatments, S106

Scorza, R., S131

Scott, D. L., Jr., S132

Scott, J. W., 33

Scow, K. M., 344

Sears, J. L., S54

Secor, G. A., S77, S117

Sedegui, M., S132

Seebold, K., S80, S126

Seed testing, quality control, reference material, S91

Seem, R. C., 902, S25, S30, S57, S79

Seifers, D. L., S80

Selinger, L. J., S11

Sellers, P. R., S117

Senecio vulgaris, Puccinia lagenophorae as biocontrol agent, S99
Seo, J. K., S68

Septoria spp.

- S. betulae, on birch, acidic fog interaction, S49

-S. musiva, on poplar, biocontrol, S35

-S. tritici, virulence variation in isolates, S27

Serlemitsos, K., S132

Serrano, M. S., S40

Serratia marcescens, on cucumber, iron role in resistance, $\mathrm{S} 73$

Sether, D. M., 1224, S80

Setosphaeria turcica, on corn, tropical and temperate climates, 322

Sha, X. Y., S126

Sha, Y., S80

Shabana, Y. M., S80

Shabi, E., S29

Shafik, H., 844

Shain, L., S80

Shapiro, J. N., S79

Sharma, H., 851

Sharp, L. P., S81

Shaver Adams, M., S85

Shaw, M. E., S109

Shaw, M. W., 492

Shea, E., S102

Shelby, R. A., S81

Shelton, K. L., S127

Shen, T. L., S12

Sherwood, J. E., 456, S4, S49

Sherwood, J. L., 98, 428, S61, S97

Shetlar, D. J., S30

Shetty, K., S81, S103

Shetty, K. G., S81

Shew, B. B., S41

Shew, H. D., S14, S35, S41

Shi, A. N., 144

Shi, Z. X., S81

Shiel, P. H., S34

Shiel, P. J., S59

Shields, J. P., S22

Shields, P. L., S27

Shim, W. B., S81

Shinners, T. C., S82

Shiomi, T., 804

Shishkoff, N., S136

Shokes, F. M., S33

Shriver, J. M., S82

Shtienberg, D., S75

Shulze, D. G., S118

Siegerist, W. C., S42

Sikinyi, T. M., S117

Sikora, E. J., S65, S82

Silene alba, anther smut, resistance pattern, S43

Sim, J., S21, S39, S55

Sim, S. T., S32

Simard, M., 494

Simpson, J., 292

Sims, J. J., S42, S84

Sinaloa tomato leaf curl virus, new subgroup III, molecular evidence, 648

Sinclair, W. A., 1372, S38

Singh, N. P., S1

Singh, R. P., 890, S82

Sinisterra, X. H., S82, S122

Sinsabaugh, R. L., S53

Sipes, B. S., S94

Sit, T. L., S56

Siuzdak, G., S58

Sivamani, E., S41

Sivaprasad, P., S82

Skaf, J. S., S82

Skaria, M., S122

Skelly, J. M., S49

Skrzeczkowski, L. J., S108

Slack, S. A., 437, S136

Slaughter, G. W., S76

Slaymaker, D., S82

Slininger, P. J., S47

Smart, C. D. (Calif.), 862, S83 
Smart, C. D. (N.Y.), 939, S59

Smedegaard-Petersen, V., 698, 735

Smilanick, J. L., S58, S64, S83, S109

Smiley, R. W., S21

Smith, A. G., S50

Smith, B. J., S5, S126

Smith, C., S89

Smith, F. D., S83

Smith, G. S., S99

Smith, J. P., S56

Smith, K. P., S83

Smith, M. T., S47

Smith, M. W., S23

Smith, O. P., S130, S133

Smith, T. H., S3

Smith-Becker, J., S83

Smither-Kopperl, M. L., 382, S83

Snetselaar, K., S132

Snyder, G., S80, S126

Snyder, K. E., S29

Snyder, W. E., 1248

Sobero, P., S32

Soil fumigation, methyl iodide, efficacy, S42

Soil solarization

-pest reduction in impatiens, in Florida, S60

— poplar, soil microflora populations, S117

- soilborne plant pathogens, in Oregon, S108

Solanum spp. (see also Potato), root-knot nematodes, virulence variation, 658

$-S$. tuberosum, somatic hybrid, bacterial wilt resistance lines, S51

Solel, Z., 1218

Solheim, H., 39

Soliman, K. M., S31

Somai, B. M., S83

Somers, D. A., 1013, S73

Sommerfeld, R. A., S56

Somodi, G. C., 33

Song, W. Y., S84

Sonoda, R. M., S84

Sorensen, L. H., S107

Sorghum

- anthracnose, genetic structure, 1087

—ergot, spread in USA and Mexico, S123

- phytoalexin, synthesis using photodiode arrayHPLC, S96

— phytoalexin biosynthesis, molecular basis, S55

- Striga asiatica on, haustorial development, 70

Sorghum analysis of ITS region, detection, S24

Sosa, M., S120

Sosnoskie, L. M., S84

Soto-Estrada, A., S84

Souik, P., S114

Souza, M. T., Jr., S84, S137

Souza, N. L., S50, S70

Soybean

-aluminum toxicity, molecular characterization, S31

-brown stem rot, residue factors, S111

- canopies, biological UV-B dosimetry, S102

- cyst nematode: biocontrol with fungus, 465; herbicide effect, S10; race population, S95; resistance in Minnesota, S16; resistance screening, S127

- flooding effect on fungi, S125

-Fusarium and Phomopsis on seed of, factors, S32

-Phomopsis seed decay, pod and stem blight, and stem canker, isolate grouping, 1306

-phosphorylation changes, syringolide-elicited protein, S82

-Phytophthora root and stem rot, flooding effect, S22

-Phytophthora root rot and damping-off, swine manure effect, S112

-Phytophthora sojae: and damping-off, swine manure application, S117; manganese in hypocotyl lesions, S113; races, in Arkansas, S125; susceptibility and microgravity, S77
- phytoplasma: clover proliferation and aster yellows groups, in Wisconsin, S116; survey in Wisconsin, S52

- powdery mildew and brown stem rot, fungicides, S3

-Pythium on roots, flooding effect, S48

- Rhizoctonia solani biocontrol with binucleate Rhizoctonia, 1056

—root-knot nematode and Caenorhabditis elegans, glycolipid comparison, S16

-rust, sequence comparison of rust species, S70

-Sclerotinia sclerotiorum: cultivar response, S118; resistance and isoflavones, S96; yield loss, S101

-Sclerotinia stem rot: control with Sporidesmium sclerotivorum, S110; resistance evaluation, S57

—-seedling blight, fungicides in Argentina, S30

- sudden death syndrome: Fusarium and cyst nematode distribution, under irrigation, S77; herbicide effect, S78; yield loss, S56

— syringolide elicitors, binding protein, S44

-white mold: crop rotation and reduced tillage effect, S33; seed transmission biology, S65

Soybean dwarf virus, yellowing strain

- sequence determination, S133

—-subcloning portions, S130

Soybean mosaic virus

—coat protein-mediated resistance, S118

- field spread, quantification, 895

—virulence determinants, S25

Spalding, R. J., S80

Spatial analysis

- nonrandomness and aggregation, letter to editor, 84

- plant pathogen populations, geostatistics and geography, S43

-SADIE, new test for aggregation, evaluation, S90

Spear, R. N., S4

Sphaeropsis sapinea, on red pine, phenolic concentration, water stress, 245

Sphaerotheca fuliginea, Milsana and BTH effect, S99

Spiegel, L., S93

Spinach

—downy mildew, new races, S19

-resistance and fungicide effect on yield and quality, in Maryland, S130

-white rust, control with resistance and fungicides, S136

Spiroplasma, engineered antibodies in plants, symposium, 1367

Spiroplasma spp., species distinction using spiroplasmavirus, $\mathrm{S} 20$

$-S$. citri: adherence to cells of vector, $89-\mathrm{kDa}$ membrane protein, S102; aster yellows phytoplasma comparison, pathogenicity, symposium, 1347; gene presence and expression, arbitrarily-primed PCR, S75; proteins, adherence to leafhopper vector, S95; vector interface, symposium, 1351; virus features, $\mathrm{S} 80$

Sporidesmium sclerotivorum, macroconidial germination, factors, S21

Spruce, blue-stain fungi and bark beetle association, 39

Stack, R. W., S84, S116, S117, S118

Stagonospora nodorum, on wheat, virulence variation in European collection, S78

Stall, R. E., 33, S5, S63, S90

Standing, K. G., S111

Stange, R. R., S84

Stanghellini, M. E., S2, S62, S121

Stanosz, G. R., 245

Starratt, A. N., 1094

Stavely, J. R., S67, S85

Stavolone, L., 1200

Steadman, J. R., S85

Stebbins, T. C., S85
Steddom, K. C., S85

Steffenson, B. J., 76, S28, S85

Steinemann, A., S37

Stenger, D. C., 782, 1174, S11, S30, S85

Stenotrophomonas maltophilia, chitinases, characterization, S103

Stensvand, A., 902

Stetina, S. R., S9

Stevens, M. K., S34

Stevenson, K. L., 1294, S10, S33, S90, S124

Stevenson, W. R., S23

Stienstra, W. C., S16, S62

Stipanovic, R. D., S40

Stipes, R. J., S128

Stockwell, V. O., 506, S85

Stolk, C., 481

Stone, J. K., 122, 1165, S108

Storer, A. J., S9, S85

Stosz, S. K., 576

Stover, E., S18

Strausbaugh, C. A., S86

Strawberry

— angular leaf spot, JMS Stylet Oil effect, S28

-anthracnose, infection ontogeny, S126

-Botrytis fruit rot, forecasting model in California, S9

-Botrytis gray mold, calcium chloride effect, S26

- crown rot and fruit rot, genotypic differences in pathogen isolates, $\mathrm{S} 123$

-fumigation, fungus pathogenicity, S100

- gray mold: plant phenology, S13; production systems, S124

-leaf blight, spatial pattern analysis, in Ohio, S90

- powdery mildew: controlled by Verticillium lecanii, in California, S63; severity assessment, S108

-root and shoot growth, rhizosphere and microflora root pathogens, S58

-soilborne pathogens, solarization for management, S42

- soil fumigation and bacteria, S100

Street, J. R., S30

Streptomyces spp.: antibiotic induction, diverse species, S7; detection in soil using PCR, S52; pathogenicity island, horizontal transfer, S12

- S. ipomoeae: on sweetpotato, diversity factors, 1179

-S. scabies: on potato, phytotoxin, 442 ; thaxtomin, pathotoxin, S2

Strickler, P., S67

Striga spp.: control by bacteria, S7; species hybrids, reproductive ability, 563

-S. asiatica: haustorial development, hosts and nonhosts, 70; on sorghum, radicle effects in haustorium, January cover photo

Strobel, G. A., S2

Stromberg, E. L., S74

Stuart, G. W., S32

Stump, W. L., S29, S86

Stutz, J. C., S86

Stylosanthes spp., anthracnose, pathogenic variation and center of diversity, S14

-S. scabra: anthracnose and insect grazing, morphogenesis, S98; anthracnose, $\mathrm{CO}_{2}$ and epidemiology, S70

$\mathrm{Su}, \mathrm{G} ., \mathrm{S} 86$

$\mathrm{Su}, \mathrm{H} ., \mathrm{S} 86$

Subbarao, K. V., 252, 1046, 1108, S8, S36, S41, S81, S86, S99

Sugar beet

-Aphanomyces seedling disease, assay, S44

-Cercospora leaf spot: fungicides and bacteria, S10; phyllosphere bacteria, S18

-fungal pathogens, actin gene sequence, assay, S114

—irrigation regime, pathogen effect, S27

- viruses, serological tests for detection, S37

-water use and disease severity, S71

-yellowing, luteovirus cause, S54 
Sugarcane

—Pythium and nematode relations, S9

-Pythium root rot, herbicide effect, 530

- ratoon stunting, pathogen detection, S20

Sugarcane mosaic virus, resistant transgenic varieties, $\mathrm{S} 1$

Suh, S.-O., S86

Sullivan, T. A., S43

Sulzinski, M. A., S86

Summerell, B. A., 30, S135

Sun, P., 592, S87, S118

Sun, Q., S41, S87

Sundaram, S., S87

Sundin, G. W., S87

Sundsbak, J., S114

Suneetha, S., S82

Sunflower

-mosaic-causing potyvirus, from Texas, S34

-white rust, resistance, S116

Sung, G. H., S87

Sung, J. M., S87

Supramana, S., S87

Susi, P., 230

Sutherland, M., S77

Sutton, T. B., S4

Sutula, C. L., S100

Swanson, S., S87

Sweat, T. A., S60

Sweetpotato

— geminivirus, identification, S55

- Streptomyces soil rot: diversity factors, 1179 ; pathogen diversity, 1179

—viruses, yield effect, S17

Szabo, L. J., S24, S50, S88

Szczech, M., 764

Tabor, G. M., S118

Tainter, F. H., S45, S60, S88, S100

Takayama, Y., S46

Talaromyces flavus, biocontrol agent, glucose oxidase and immunocytochemistry, 576

Tally, A., S18, S51, S88

Tam, Y. K., S53

Tanaka, M., S88

Taylor, J. D., S91

Taylor, S. E., S68

TeBeest, D. O., S55, S125, S126

Teixidó, N., 960

Téliz, D., S67

Tenberge, K. B., 744, 1020

Tennant, P., S84

Termorshuizen, A. J., 481

Tessmann, D. J., S88

Teufel, K. M., S86

Tewari, I., S89

Tewari, J. P., S52, S65, S82, S89, S101

Thaxton, P. M., S99

Thielaviopsis basicola, on cotton, histology, S93

Thies, J. A., S89

Thinopyrum intermedium, barley yellow dwarf virus resistance source, 851

Thomas, C. E., S95

Thomas, C. S., S89

Thomas, M., S14

Thomashow, L. S., S59, S80

Thompson, D. C., S89

Thompson, I. A., S118

Thompson, M., S111

Thordal-Christensen, H., 698

Tian, H., S89

Tian, T., 164

Tiffany, L. H., S115

Tilletia spp.: bunt and smut disease, teliospore germination, 260; teliospore germination, inhibition by Ustilago hordei, $\mathrm{S} 49$

-T. indica: teliospore germination, stimulation, S9; on wheat, detection by PCR, S29

Timko, M. P., 70

Timmer, L. W., 724, 1218, S104
Tiourebaev, K. S., S4, S89

Tirilly, Y., 234

Tisserat, N. A., S93, S96

Tobacco (see also Nicotiana spp.)

—black shank, resistance and rating systems, S44

—blue mold: harpin effect, S65; suppression by fungicides, S50

—disease resistance, $m y b$ gene, S101

—geminiviruses, whitefly-transmitted, molecular diversity, $\mathrm{S} 92$

— myb1 promoter, pathogen-inducible, S101

- peanut stunt virus, cytoplasmic inclusions, 1192

- Phytophthora parasitica, virulence diversity, 205

- transgenic, Ralstonia solanacearum, resistance from human lactoferrin, 730

-Virgin A Mutant, potyvirus resistance, S1

Tobacco mild green mosaic virus, isolate diversity, S8

Tobacco mosaic virus

- defective replicase gene, resistance, $\$ 40$

$-N$ gene elicitor, characterization, S39

—satellite, variants, 514

- systemic resistance, harpin induction, S74

- tetracycline-induced accumulation, in transgenic tobacco, $\mathrm{S} 75$

Tobacco necrosis virus

-ELISA for detection, S100

- systemic resistance, salicylic acid biosynthetic genes, 678

Tobacco ringspot virus, in Xiphinema americanum

- cover photo, September

-localization, 885, S127

Todd, J. W., S33, S127

Tomaru, M., S69

Tomas, A., S32

Tomato (see also Lycopersicon spp.)

-bacterial canker, ingress through hydathodes, 525

-bacterial speck, leaf factors and toxins, 1094

-bacterial spot: control with compost extracts, S3; plant activator, S55; race 3 in Florida, 33

-bacterial wilt, soil amendment effect on survival, 300

— begomoviruses, in Puerto Rico, S42

- cucumber mosaic virus, replicase mediated resistance, 1101

—disease management strategy, in Ohio, S99

- foliar and fruit diseases, control by compost and Actigard, S63

-Fusarium crown and root rot, fertilizers and management, S23

—geminivirus DNA-A component, S81

-IPM practice, in Alabama, S82

-late blight: resistance induced, S100; specificity in Ecuador, 265

-lesion nematode, marigold as control, S3

-Pythium infection: asymptomatic, 234; paratracheal tissue, cover photo, March

- Sinaloa tomato leaf curl virus, new subgroup III, molecular evidence, 648

- Southern blight, factors and yield, S12

-tospovirus resistance, in Brazil, S28

Tomato bushy stunt virus

-host-specific RNA elements, S70

- movement genes, defective interfering RNAs, S75

-purification, movement proteins, S21

Tomato chlorosis virus, whitefly-transmitted, 402

Tomato leaf crumple virus, nucleotide sequence, S44

Tomato mottle virus

- protection in field, S65

-on tobacco, transformation by coat protein, $\mathrm{S} 82$

Tomato ringspot virus, on pelargonium, detection, S40

Tomato spotted wilt virus

—epidemiology and pathosystem in Mexico, S68

- glycoproteins, thrips midgut protein interaction, 98

-monoclonal antibodies and resistance, $\mathrm{S} 40$

- N gene, comparative resistance, S34

—on peanut, resistance, $\mathrm{S} 33$ -receptor in thrips vector, immunoprecipitation, S61

— thrips protein binding, 63

-tissue blot immunoassay, development, S97

Tomato yellow leaf curl virus

- detection and identification, immunoassay, 1302

-resistance in Lycopersicon hirsutum, 910

Tonkyn, D. W., 1248

Toojinda, T., S16

Tooley, P. W., S29, S132

Torbert, K. A., 1013

Torés, J. A., 614

Torrance, L., 230, 1302

Torres Jerez, I., S92

Toxins

- thaxtomin A, potato scab, 442

$\alpha$-tomatine, on tomato, fungal sensitivity to, 137

Toxoptera citricida, citrus tristeza virus relation, infection pattern in Costa Rica and Dominican Republic, 621

Trail, F., S4, S89

Trapero-Casas, A., 983

Traunfeld, J. H., S57

Travis, J. W., S68, S130

Treber, M., S102

Tremblay, D., S19, S89

Trevathan, L. E., S121

Trialeurodes vaporariorum, tomato chlorosis virus vector, 402

Trichoderma spp., protoplast fusion, variable progeny, S36

- T. harzianum: on apple, exochitinase gene from, $\mathrm{S} 8$; biocontrol strains, mushroom green mold relation, S69; on creeping bentgrass, in rhizosphere and phylloplane, transformation, 129; on mushrooms, phylogenetic analysis, S16; in wood, mushroom composts, S14

-T. longibrachiatum, transformants, Pythium biocontrol in cucumber, 673

$-T$. virens, cotton seed treatment, phytoalexin induction, $\mathrm{S} 40$

Tricoli, D. M., S34

Triplett, E. W., S46

Trout, C. L., S90

Trujillo, E. E., S122, S123

Truta, A. A. C., S64

Tsuge, T., 804

Tubajika, K. M., S90

Tudela, A. F., S9

Tudor, S. M., S90

Tudzynski, P., 1020

Tuitert, G., 764

Tuori, R., S78

Turechek, W. W., 1294, S90

Turfgrass (see also Agrostis stolonifera and Bentgrass)

— azoxystrobin uptake and redistribution, S6

- dew duration measurement, impedance leaf wetness sensor, S93

-dollar spot: paclobutrazol effect, S62; suppression by hypovirulent isolates, 788

- dollar spot and nutrition, factors, S30

-endophyte infection, volatile compounds, S94

- gray leaf spot, cultural factors, S137

- nematodes, fenamiphos-alternatives for control, S137

-Pythium spp., detection using dot blot hybridization, S21

- trifloxystrobin, S2

Turina, M., S6, S74

Turkington, T. K., S52, S65

Turnbull, G. D., S94

Turnip mosaic virus

-helper component protein, purification, S94

—isolate variability, 1200

Tuzun, S., S1, S65, S74, S100, S103

Uchida, J. Y., S45, S46, S90

Uddin, W., S90 
Uehara, T., S88

Ullman, D. E., 98, 1224, S61, S72, S97

Ullrich, B., S91

Ullrich, M., S91

Ulocladium atrum, biocontrol agent for Botrytis on cyclamen, 568

Umaharan, P., 1262

Uncinula necator

- fungicides, resistance-management strategy, S97

-on grape, inoculum trapping system, S35

Uncinuliella australiana, haustorial ultrastructure, S63

Uphoff, M. D., S101

Urban, S. C., S72

Urena, A., S123

Uromyces spp., on legumes, phylogenetic relations, ITS region analysis, $\mathrm{S} 88$

-U. appendiculatu, on bean: chlorothalonil application, S115; races in North Dakota, S114; resistant germplasm, S85; survival in North Dakota, S111

Usall, J., 960

Ustilago spp.

-U. hordei: cell morphology and pigmentation, factors, S54; mating inhibitor, 456; mating, pheromone-related agonists and antagonists, S49; mating response, pheromone, $\mathrm{S} 4$

-U. maydis: glucanase isolation, $\mathrm{S} 58$; matingimpaired mutants, S132; on sweet corn, silk age and pollination effect, S24

Uyemoto, J. K., 1231, S91

Uzunovic, A., S30, S47, S101

Vachon, J., 442

Vaiciunas, S. S., S137

Vajna, S131

Valette, C., 1141

Valinsky, L., S6

Valkonen, J. P. T., 311, 1073

Vallejos, C. E., S72

Valmeekam, V., S91

Valverde, R. A., S17, S21, S39, S21

Van Alfen, N. K., S59

van Beckhoven, J. R. C. M., 795

van Bruggen, A. H. C., S34, S86, S99

Vancauwenberge, J. E., S118

Vance, C. P., S73

Vance, V. B., S3

Vande Hei, R. L., S61

van den Berg-Velthiuis, G., 1315

van den Bosch, F., 481

van den Bulk, R. W., S91

van den Heuvel, J. F. J. M., S29, S39

van der Beek, J. G., 658

van der Lee, T., 1315

Van der Meij, J., S83

van der Wilk, F., S29, S39

van der Wolf, J. M., 795

van der Zouwen, P. S., S91

van der Zwet, T., S129, S132

van de Wetering, F., 63

Van Eck, J. M., S83

VanEtten, H. D., 137

VanGessel, M. J., S84

VanHouten, W., S72

Vanlerberghe-Masutti, F., 205

van Riessen, H. W., S91

VanTaoi, T. T., S22

van Twisk, C., 795

van Wyk, P. S., S116

Vargas-Ayala, R., S122

Varma, A., S7

Vasquez, S. J., S78, S91, S108

Vazquez, A., S72

Veenbaas-Rijks, W. J., 922

Vegetables, bacterial leaf spots, characterization in Oklahoma, S104

Velasquez, L., S89

Velasquez-Valle, R., S123
Venard, P., 205

Veneau, J., 472, 740

Venette, J. R., S34, S91, S111, S114, S115, S116

Venturia inaequalis

—ascospore discharge, factors, 902

-ascospore maturation discharge, in Croatia, $\mathrm{S} 45$

-Microsphaeropsis sp. interaction, cytochemistry, 605

Vera Cruz, C. M., S91

Verbeek, M., S29, S39

Verchot, J., S42

Verticillium dahliae

-on broccoli, reduction mechanism, S81

-on cauliflower: crop rotation and irrigation effect, 1046; disease management, 1108

- comparison in several crops, S107

- genetic characterization, PCR and vegetative compatibility, S8

_-green fluorescent protein, S78

- host specificity, S8

- population density in soil, botanical extracts, S128

-on spearmint and peppermint, vegetative compatibility, S23

Vesonder, R. F., S92

Vicia spp., Rhizobium and Botrytis interaction in seedlings, S25

-V. faba, Botrytis infection, resistance, S66

Victry, K. D., S52

Vidaver, A. K., 730, S47, S133

Vidavsky, F., 910

Viljoen, A., S116

Villar, M., 156

Villarreal, A., S92

Viñas, I., 960

Vinca, Pythium damping-off, biocontrol:

—with Rhizoctonia, S124

-with Trichoderma, S13

Viquez, O. M., S73

Viruses

- closteroviruses, aphid-transmitted, genomic organization and evolution, S46

- coat protein: analysis by mass spectrometry, S111; neutralizing antibody, HIV-1 epitope, S35

- Geminiviridae, evolutionary history, CP gene core region, $\mathrm{S} 120$

_-geminiviruses, pathogen-derived resistance, $\mathrm{S} 122$

- potyviruses: serological relations, 965 ; singlechain antibodies, cloning, S58

- soil, extraction and detection using PCR, S53

- synergism between unrelated viruses, ultrastructure, S58

Vivanco, J. M., S133

Vivar, H. E., S16, S77

Viveros, M., S12

Voelksch, B., S7

von Broembsen, S. L., S23, S92

Vyn, T. J., S33

Waalwijk, C., 30

Wada, M., S69

Wadsworth, M. L., S109

Waight, K., S57

Walcott, R. R., S92

Waldenmaier, C. M., S3, S128

Walgenbach, D. D., S16

Walk, T. E., S127

Walker, J. T., S92

Walker, M. A., S6

Walker, N. R., S92, S93, S127

Walker, S. L., S93

Walkinshaw, C. H., S93, S127

Wall, G. C., 774, S93, S123

Walla, J. A., S35, S93

Wallace, H., S17

Walsh, B., S93

Waly, E., S66

Wang, C., S94
Wang, D., 376

Wang, H., S94

Wang, H.-L., S94

Wang, J. (Ky.), S131, S133

Wang, J. (Ind.), 1269, S17

Wang, J.-S., S65

Wang, K., 811

Wang, K.-H., S94

Wang, M., S40, S122

Wang, R. Y., S94

Wang, S. (Ark.), 885, S94, S95, S127

Wang, S. (Iowa), S63

Wang, X. (Iowa), S118

Wang, X. (N.Mex.), S109

Wang, Y., 1101

Wang, Y. H., S95

Wangsomboondee, T., S95

Ward, K. T., S95

Ward-Rainey, N., 1179

Warren, H. L., S128

Watada, A. E., S18

Watanabe, K. N., 1073, 1205

Watanabe, Y., S69

Watermelon (see also Melon)

- fruit blotch, PCR primers for identification of pathogen, S84

- gummy stem blight, fungicides and yield, S125

- gummy stem blight and anthracnose, fungicides and MELCAST, S27

-seedling damage, yield loss components, S24

Watermelon silver mottle virus, ambisense M RNA comparison, 351

Watson, A. K., S135

Watson, M. T., 164

Wax, L. M., S10

Wayadande, A., 1351, S95, S102

Wearing, L. P., S95

Webb, C., S95

Webb, K., S131

Webster, D. E., S95

Webster, R. K., S17, S106

Wechter, W. P., S96

Wedburg, J. L., S52

Weeds

-biocontrol, Uromyces rumicis relation, S129

- pathogens, host-specific response, S15

Wegulo, S. N., S68, S96, S118

Wehner, F. C., 366

Wei, Z.-M., S65, S67, S69, S74, S78, S87, S96

Weidemann, G. J., S72

Weiland, J. J., S114

Weingartner, D. P., S19

Weinzierl, R. A., S38

Weiss, B., S88

Welch, T. L., S133

Weller, D. M., S59, S74, S80

Wellings, C., S81

Welty, L., S19

Welz, H. G., 322

Weng, Z., S96

Wergin, W., 576

Wesenberg, D., S85

West, C. P., S19

Westphal, A., S96

Wetzel, H. C., III, S96

Wharton, P. S., S96

Wheat

- crater disease, characterization, 366

- curl mites, virus transmission of High Plains virus, S80

-deoxynivalenol, identification by mass spectrometry, S113

-Fusarium graminearum, spike infection, S73

-Fusarium head blight: recombinant inbred lines, S116; resistance, Chinese lines, S56; resistance inheritance in hybrids, S84; Triticium dicoccoides as resistance source, $\mathrm{S} 118$

— head scab, biocontrol strategy, S47

— Karnal bunt, teliospore detection, sieving, S131 
-leaf rust: plant density and species proportion factors, 708; slow-rusting gene, S82; slow-rusting gene Lr46, 890; yield and kernel weight, fungicide effect, S121

-Microdochium nivale on, soil top dressing effect, S66

- powdery mildew, major gene from einkorn to common, 144

-Ptr necrosis toxin, host metabolism role, $\mathrm{S} 112$

-rhizosphere: bacteria, lactone mediated signaling, S71; manganese, bacteria, S118

-root rot, fungi associated, in Mississippi, S121

— scab, deoxynivalenol effects, in Wisconsin, S114

- signal transduction, Ptr ToxA, action, S50

- smut and Karnal bunt, S19

-stem rust: new resistance sources, S44; specific resistance, 171

- take-all, control in China, S35

- tan spot: infection period modeling, S21; insensitivity to toxin, S30

- $\tan$ spot and Fusarium head blight, previous crop effect, S116

Wheat soilborne mosaic virus, yield and grain quality effect, S42

Wheat streak mosaic virus

-brome streak mosaic virus comparison, not Rymovirus, 782

— protein-protein interactions, S30

-resistance in soft white winter wheat, S59

- sequence and phylogeny, S85

—in winter wheat, seedling evaluation, S112

Wheeler, D. M., S91

Whigham, K., S78

Whistler, C. A., S85

White, D. G., 972

White, F. F., S101

White clover, peanut stunt virus on, S61

White pine (see also Pine)

- Armillaria on, ecology in Idaho, S60

-blister rust: genetic structure in populations, 1187; insects involved in spermatiation, S67

Whitfield, A. E., S97

Whittington, D. P., S84, S132

Wick, R. L., S135, S137

Widmer, T. L., 389, S97

Widstrom, N. W., S53

Wiebold, W. J., S99

Wiecko, A. T., S93, S123

Wikler, K., S9, S97

Wilcox, W. F., S25, S30, S97, S98

Wilkinson, H. H., S8

Willard, L. H., S38

Williams, H., S123

Williams, J. G., S100

Williams, M., S102

Williams, P. H., 1068

Williams, W. P., S98

Wilson, A. D., S97

Wilson, C. L., 282, S21

Wilson, J. P., S97

Wilson, L. L., 536, 950, S68

Wilson, M., S27, S44

Wilson, P., S98

Wilson, S. K., S92

Windells, C. E., S24

Windham, G. L., S98

Wingfield, M. J., S97

Wintermantel, W. M., S98

Wisler, G. C., 402, 1040, S54

Wisniewski, M., 282

Wolf, D., 1101
Wolf, T. K., S129

Wolff, D. W., S104

Woloshuk, C. P., S28, S81, S98

Wolpert, T. J., S18, S20

Wong, F. P., S98

Wong, K. W., S136

Wong, S.-M., S27, S102

Woo, S., 30

Wood

-brown rot and white rot, detection with PCR assay, S43

—debris, ergosterol measurement, S45

-fungal sapstain, in Canada, S101

Wood, D. L., S9, S85

Wood, D. W., S71

Woods, D. M., S98

Wrather, J. A., S99

Wright, D. S., S60

Wright, R. J., S99

Wu, B. M., S99

Wu, J., S58

Wu, W., S92

Wuest, P. J., S4, S14, S50, S134

Wurms, K. V., S99

Wyatt, S. D., S59, S120

Wyenandt, C. A., S99

Wyss, G. S., S99

Wyss, U., S100

Xanthomonas spp., on citrus and cotton, protein signal, S23

-X. campestris: on anthurium, survival in crop debris, S23; on cole crops, lineages, S56; on crop debris and weeds, survival, S6; DF pheromone, gene identification, S72; on geranium, distribution, S86; HR elicitor, characterization, S87; insertion sequence and distribution among xanthomonads, S49; on pepper, resistance and mutations of avrBs2 locus, S49; Pseudomonas syringae comparison, molecular analysis of genetic locus, S63; race T3, single locus resistance, S5; on sorghum, DNA probes for detection, S66; on tomato, acquired resistance from Actigard, S124; on tomato, bacteriocins and race 3 antagonism, S90; on tomato, race 3, 33; xanthomonadin pigments, biological role, $\mathrm{S} 72$

-X. oryzae: in Arabidopsis, resistance elicitation, AvrXa10, S101; protein interaction with avirulence gene, S117; on rice, aggressiveness genes, mutagenesis vectors, S114; on rice, avirulence gene homolog, S4

Xia, J. Q., S100, S126

Xiao, C. L., 1046, 1108, S100

Xie, W., S113

Xiong, Y., S132

Xiong, Z., S1, S51, S96

Xiphinema spp.

$-X$. americanum: tobacco ringspot virus, localization, 885; transmission-related virus attachment, monitoring, S94

$-X$. index, grapevine fanleaf virus vector, maintenance in culture, $\mathrm{S} 100$

Xu, M. Q., S40

Xu, X. L., S100

$\mathrm{Xu}, \mathrm{X} . \mathrm{-M}, 1000$

$\mathrm{Xu}, \mathrm{Z} ., \mathrm{S} 100$

Xue, B., S49

Xue, L., 359

Xylella fastidiosa

-detection, S5

-on grape, detection with culture, ELISA, and PCR, S83
Yan, J., S69

Yan, Z., S100

Yang, B., S101

Yang, C.-H., 330

Yang, D. Q., S30, S101

Yang, J., S101

Yang, S. M., S101

Yang, X. B., 490, 592, S21, S36, S78, S87, S96,

S101, S110, S111, S113, S115, S118

Yang, Y., S95, S101

Yang, Z., S52

Yao, M. K., S102

Yates, D., S70

Ye, F., 1351, S95

Yeh, S.-D., 351, S54

Yelle, S., S102

Yoshimura, M. A., S102

Yot, P., S58

Young, N. D., S16

Young, R. J., S129

Young, S. A., S38, S117

Young, T., S2

Yu, H.-H., S102

Yu, J. (Okla.), S102

Yu, J. (La.), S98

Yu, W. J., S114

Yuen, G., S69, S102, S103, S119

Yuen, J. M. F., S67

Zack, J. W., S57

Zadoks, J. C., 754

Zaitlin, M., S98

Zambino, P. J., S102

Zang, L., S81, S103

Zavala, M. E., 292

Zavaleta-Mejía, E., S67, S68

Zehnder, G. W., S65, S82

Zeigler, R. S., 223, S19

Zelcer, A., 1101

Zeller, K. A., S103

Zemetra, R. S., S59

Zeyen, R. J., S50, S103

Zhan, J., 1330

Zhang, A. W., 1306

Zhang, J., S84

Zhang, J. X., S12, S62, S103, S122

Zhang, L., S119

Zhang, S., S103

Zhang, W., 450

Zhang, X., S44

Zhang, Y.-P., 1231, 1238

Zhang, Z., 730, S69, S103, S119

Zhao, G., S23

Zhao, Y., S103

Zhao, Y. F., S104

Zheng, J., S38, S47

Zheng, X. Y., S104

Zhong, B., S69

Zhong, H., S84

Zhou, T., 788, S104

Zhou, X. G., S104

Zhu, H., S104

Zhu, H. Y., S49

Zhu, W.-G., S101

Zhu, Y., S69

Zidack, N. K., S104

Ziegler, A., 230, 1302

Zijlstra, C., 658

Zitko, S. E., 1218, S104

Zitter, T. A., S104

Zuccini yellow mosaic virus, mobility analysis and coat protein variability, S54

Zwankhuizen, M. J., 754 